\title{
Construções causativas no português antigo e clássico: O scrambling e a emergência da marcação de caso excepcional
}

\author{
Causative Constructions in Old and Classical Portuguese: \\ Scrambling and the Emergence of Exceptional Case Marking
}

\begin{abstract}
Aroldo Leal de Andrade*
Universidade Estadual de Campinas (Unicamp), Campinas, São Paulo, Brasil. aroldo.andrade@gmail.com
\end{abstract}

Resumo: Este texto tem um duplo objetivo: apresentar um quadro da variação e mudança envolvendo diferentes construções causativas no português antigo e clássico, a partir de um estudo baseado em corpus; e apresentar uma análise para a emergência da construção de marcação de caso excepcional no complemento de verbos causativos. Proponho, num quadro minimalista, que o licenciamento do causado na posição entre os verbos causativo e infinitivo surge a partir da reanálise de uma posição A' na periferia do sintagma infinitivo, resultante de uma operação de scrambling. Até o final do português antigo, a construção não seria possível devido a uma correlação entre propriedade de "ordem livre de palavras" quanto à configuracionalidade discursiva e o alinhamento morfossintático inverso dos argumentos verbais no complemento infinitivo.

Palavras-chave: Português antigo; Português clássico; Verbos causativos; Marcação de caso excepcional; Configuracionalidade discursiva.

\footnotetext{
* Agradeço a Heloisa Salles pela cooperação numa versão prévia; às plateias do SILEL 2011 e dos Colóquios do ForMA/Unicamp 2012, pela interlocução; a Juliana Trannin, pela cessão de dados de sua dissertação; às sugestões de dois pareceristas anônimos; e à Fapesp pelo apoio financeiro (processo 2011/19235-2). Este trabalho relaciona-se ao projeto temático Fapesp "A língua portuguesa no tempo e no espaço" (processo 2012/06078-9). Eventuais erros e inconsistências são de minha responsabilidade.
} 
Abstract: This text has a twofold goal: to give a picture of variation and change involving different causative constructions in Old and Classical Portuguese from a corpus-based study, and to present an account for the emergence of the Exceptional Case Marking construction in the complement of causative verbs. I propose, in a minimalist framework, that the licensing of the causee in the position between the causative and the infinitival verb arises from the reanalysis of an A' position at the periphery of the infinitival phrase, resulting from a scrambling operation. Until the end of Old Portuguese the construction would not be possible due to a correlation between the property of "free word order" regarding discourse configurationality and the inverse morphosyntactic alignment of the verbal arguments in the infinitival complement.

Keywords: Old Portuguese; Classical Portuguese; Causative Verbs; Exceptional Case Marking; Discourse Configurationality.

Recebido em 06 de fevereiro de 2014. Aprovado em 20 de maio de 2014.

\section{Introdução}

As construções causativas do português apresentam uma variação que vem suscitando interesse de pesquisadores de diferentes perspectivas teóricas. Os trabalhos prévios ora enfocam a questão derivacional (GONÇALVES, 1999), ora os efeitos de sentido que o uso de uma ou outra construção estabelece (SOARES DA SILVA, 2005). O estudo dessa variação sob uma perspectiva sincrônica é, por si só, instigante, já que três grandes tipos de construções são encontrados no complemento de verbos causativos (deixar, fazer, mandar) do português europeu moderno, conforme (1): ${ }^{1}$
a. "União de orações" (fazer infinitivo)
O João fez escrever o trabalho aos alunos.
b. Marcação de caso excepcional
O João fez os alunos escrever o trabalho.

\footnotetext{
${ }^{1}$ O termo "união de orações” foi proposto em Raposo (1981). Utilizo-o entre aspas para demonstrar que não compartilho da análise que ele encerra, desenvolvida no âmbito da gramática relacional. Já o termo "fazer-infinitivo" é adaptado do francês 'faire-infinitif', proposto em Kayne (1975), da mesma forma que fazer-por ('faire-par').
} 


\section{c. Infinitivo flexionado \\ O João fez os alunos escreverem o trabalho.}

No campo diacrônico, os trabalhos têm buscado relacionar mudanças qualitativas ou quantitativas a outras alterações (léxico-) gramaticais observadas em diferentes períodos da história do português europeu (MARTINS, 2004; ANDRADE, 2010; TRANNIN, 2010) e brasileiro (BORGES, 2008). O presente trabalho se insere na linha de pesquisa diacrônica, com enfoque na implementação da mudança que levou ao surgimento da construção de marcação de caso excepcional em fases mais recuadas do português.

Ao se observar o subconjunto dos trabalhos com enfoque no português antigo, nota-se uma certa dúvida quanto ao espectro de variação relativa a essas construções. Nos trabalhos dos filólogos que se debruçaram sobre a sintaxe histórica do português há opiniões divergentes: Said Ali (1964, p. 58-59) diz que seria obrigatória a atribuição de caso dativo ao sujeito do verbo infinitivo (o que corresponde, na linguística formal, à construção de "união de orações"); já Dias (1933, p. 336) e Pereira (1935, p. 285) teriam encontrado alguns dados em que o sujeito do infinitivo receberia caso acusativo (ou seja, a construção de marcação de caso excepcional). Na linguística moderna, houve duas tentativas de aproximação do problema. Davies (1996), em amplo estudo sobre dados do português antigo, do português europeu moderno e do português brasileiro, afirma que a construção de "união de orações" seria a opção não-marcada no português antigo. Finalmente, Martins (2004) propõe que o infinitivo flexionado teria surgido nesse contexto em razão de um tipo preciso de ambiguidade que teria existido entre orações encaixadas e matrizes.

Diante desse debate, a hipótese que busco verificar, baseada numa intuição prévia sobre os dados que converge com a posição de Said Ali (1964), é que a construção de marcação de caso excepcional era totalmente inexistente no português antigo, e que tampouco a construção de infinitivo flexionado estava disponível nessa gramática. A referida hipótese me levou a trabalhar para a consecução de dois objetivos. Primeiro, o de proceder a uma nova observação empírica, por julgar que os supostos dados de sujeito marcados com caso acusativo ("excepcionais", num duplo sentido) poderiam ser reinterpretados com base numa sistemática de classificação mais refinada. Esse passo descritivo mostrou-se crucial 
para fazer face à opacidade dos dados, que apresentam diversos casos de ambiguidade entre as diferentes construções em (1), e de algumas dessas com uma quarta, fazer-por, um subtipo da "união de orações", hoje só usada sem o oblíquo:

$$
\begin{aligned}
& \text { a'. "União de orações" (fazer-por) } \\
& \text { O João fez escrever o trabalho (pelos alunos). }
\end{aligned}
$$

Essa tarefa é precedida, no entanto, da observação do quadro da variação entre as construções causativas em variedades sincrônicas do português: português europeu moderno (PEM) e português brasileiro (PB), por se supor que a compreensão da sintaxe das gramáticas atuais de uma mesma língua - entendida como objeto historicamente construído - pode auxiliar na análise de fases mais recuadas, o que se examina na seção 2. Em seguida, tendo em vista a análise quantitativa de uma base de dados do português antigo (PA) e do português clássico ( $\mathrm{PCl})$, elaborei quadro semelhante no eixo diacrônico, a partir da identificação do momento preciso em que surgiu a construção de marcação de caso excepcional na história do português.

O segundo objetivo do trabalho se desenvolve a partir das opções de variação disponíveis no português antigo e no português clássico, identificadas na seção 2 . Considerando que o português antigo era de fato desprovido da construção de marcação de caso excepcional, qual seria a razão para que a variação se limitasse às opções em (1a) e (1a')? Uma resposta para essa questão é considerada na seção 3, em termos de uma impossibilidade tipológica vinculada à propriedade de configuracionalidade discursiva do português antigo. Essa mesma propriedade seria responsável pela obrigatoriedade da subida de clíticos nessa gramática, observada para esse contexto em vários trabalhos, inclusive Davies (1996). A partir disso, ofereço uma explicação para o surgimento da marcação de caso excepcional na seção 4.

Este trabalho segue a perspectiva teórica de princípios e parâmetros, e mais especificamente o programa minimalista, tal como foi proposto em Chomsky $(2001 ; 2008)$. Em consonância com essa visão, considero uma periodização para a história do português que toma como critério a quantificação de dados linguísticos, combinados a uma perspectiva de mudança abrupta, seguida de um período de espalhamento da construção inovadora por uma comunidade de fala. Por isso, é o 
início, e não o final, de determinados estágios de transição que é tomado como momento da mudança de um período a outro. Dessa forma, o PA abrangeria o início do século XII até meados do século XV; o $\mathrm{PCl}$, de meados do século XV ao final do século XVII, e o PEM, do século XVIII aos dias atuais (ver GALVES, NAMIUTI; PAIXÃO DE SOUSA, 2006).

\section{As construções causativas e sua distribuição em variedades do português}

As construções causativas perifrásticas apresentam a seguinte estrutura argumental, abstraindo-se do problema da ordem linear (em que $\mathrm{V}_{\text {caus }}$ indica o verbo causativo, e $\mathrm{V}_{\text {inf }}$, o verbo infinitivo):2

(2) Esquema de estrutura argumental de uma perifrase causativa causador $\mathbf{V}_{\text {caus }}$ causado $\mathbf{V}_{\text {inf }}$ (arg. int. I) (arg. int. II)

Em (2), todos os argumentos verbais aparecem em itálico: o causador indica o referente agentivo, controlador da situação causal; o causado é, ao mesmo tempo, o recipiente da ação do causador e o iniciador da ação precipitada pela primeira ação; o arg. int. I indica o objeto direto, numa análise tradicional, e o arg. int. II indica o objeto indireto beneficiário. Os dois últimos elementos evidentemente ocorrem a depender da transitividade verbal e são nomeados de uma forma nãotradicional, a fim de evitar um "imbróglio terminológico", já que, por vezes, o argumento causado pode receber caso acusativo ou dativo, como já se mencionou e se explica com mais pormenor logo a seguir.

Além da questão da ordem dos termos da oração no domínio encaixado (causado pós-infinitivo na união de orações e pré-infinitivo nas demais construções), já observável em (1), as construções causativas diferenciam-se quanto aos seguintes aspectos:

- a marcação de caso abstrato, particularmente do argumento causado;

\footnotetext{
${ }^{2}$ Este trabalho não analisa a construção causativa $V_{\text {caus }}$ [dativo] [oração subjuntiva], que sempre esteve presente na história do português europeu, desde o PA, e merece ser incluída em estudos futuros.
} 
- a ocorrência da subida de clíticos.

Tais aspectos são exemplificados a partir da pronominalização dos argumentos do domínio infinitivo em (3)-(6) (sendo indicada entre parênteses a função gramatical do elemento sublinhado, em cada sentença):

"União de orações" (fazer-infinitivo)

a. O João fê-lo escrever aos alunos.

(arg. int. I)

b. O João fez-lhes escrever o trabalho.

(causado)

(4) “União de orações" (fazer-por)
a. O João fê-lo escrever (pelos alunos).
(arg. int. I)

b. O João fez escrever o trabalho (por eles / Ø). (causado)

(5) Marcação de caso excepcional
a. O João fez os alunos escrevê-lo.
b. O João fê-los escrever o trabalho.
(arg. int. I)
(causado)

(6) Infinitivo flexionado
a. O João fez os alunos escreverem-no.
(arg. int. I)
b. O João fez eles escreverem o trabalho.
(causado)

Essas possibilidades, aplicadas a um verbo infinitivo transitivo, demonstram que o causado recebe caso: dativo em fazer-infinitivo; oblíquo em fazer-por; acusativo na construção de marcação de caso excepcional, atribuído por $\mathrm{V}_{\text {caus }}$; e nominativo na construção de Infinitivo Flexionado, atribuído pelo $\mathrm{V}_{\text {inf }}$. Note-se ainda que, no que tange à construção fazer-infinitivo, o causado recebe acusativo se o verbo infinitivo for intransitivo, como se demonstra em O João fêe-los sair.

No que respeita à subida de clíticos, ou seja, a ocorrência de um clítico pronominal selecionado pelo $\mathrm{V}_{\text {inf }}$ junto ao $\mathrm{V}_{\text {caus }}$, nota-se que ela ocorre com o arg. int. I ou com o causado, em (3) e (4) (exceto com o causado em fazer-por, devido à inexistência de clítico oblíquo). Por outro lado, a subida de clíticos não se verifica em (5) e (6), a não ser com o causado na marcação de caso excepcional, por ser $\mathrm{V}_{\text {caus }}$ o primeiro núcleo verbal junto ao qual ele pode se hospedar. Essa suposição se baseia na ideia de que o clítico é um núcleo que se move para um outro núcleo com 
pelo menos os mesmos traços que ele, estando em causa os traços-phi (ver a noção de defective goal em ROBERTS, 2010a).

Nesse quadro, a construção de infinitivo flexionado se destaca das demais, por apresentar, complementarmente, morfologia verbal com flexão de número e pessoa, o que possibilita caracterizá-la como uma configuração bioracional.

As construções mencionadas anteriormente se distribuem em duas variedades do português sincrônico como se mostra na Tabela 1 .

Tabela 1- Construções causativas em variedades sincrônicas do português

\begin{tabular}{l|ll}
\hline Construção/Variedade & PEM & PB \\
\hline Fazer-infinitivo & $\checkmark$ & $\mathbf{x}$ \\
Fazer-por & $\mathbf{x} !$ & $\mathbf{x} !$ \\
Marcação de caso excepcional & $\checkmark$ & $\checkmark$ \\
Infinitivo flexionado & $\checkmark$ & $\checkmark$ \\
\hline
\end{tabular}

A inexistência de fazer-infinitivo em PB pode ser explicada em termos da perda da marcação de caso dativo com a preposição $a$, mudança que deu lugar ao desuso do paradigma de clíticos correspondente ao dativo (lhe/lhes; ver TORRES MORAIS; SALLES, 2010). No que respeita à construção de fazer-por, observa-se um uso restrito, tanto em PEM quanto em PB, pois em nenhuma dessas variedades o causado pode ser expresso em sua forma nominal plena, sendo que no PB o verbo mandar permitiria uma construção muito semelhante ilustrada em (7a) (ver SALLES, 2011). Nas duas variedades, via de regra, a ausência da expressão do causado é considerada um indício de fazerpor (dado o status formal do causado como oblíquo e, portanto, capaz de ser omitido): ${ }^{3}$

(7) Fazer-por em Português Brasileiro

a. O João mandou lavar o carro com os empregados.

b. O João mandou lavar o carro.

$\mathrm{Na}$ próxima seção, dedico-me à identificação do quadro de construções disponíveis no $\mathrm{PA}$ e no $\mathrm{PCl}$, quando também enceto a

\footnotetext{
${ }^{3}$ Para um estudo pormenorizado sobre as diferenças entre PB e PEM, recomendo a leitura de Gonçalves e Duarte (2001), em que são indicadas também preferências quantitativas de uso de diferentes construções.
} 
discussão sobre o problema da identificação precisa das construções em dados de corpora do português.

\section{As construções causativas no português antigo e clássico}

O estudo sobre corpus foi realizado a partir de uma base de dados composta por dois conjuntos de textos. O primeiro incluiu textos do PA, a maioria dos quais acessíveis online a partir do Corpus Tycho Brahe (GALVES; FARIA, 2010; referido por CTB) do qual foram extraídos os textos em (8a,c), e do Corpus Informatizado do Português Medieval (XAVIER, 2011; referido por CIPM) do qual foram extraídos os textos em $(8 b, d)$. Os dados foram coletados manualmente, devido à inexistência de anotação sintática para eles, e totalizaram cerca de 640 sentenças: ${ }^{4}$

(8) Corpus utilizado para a criação da base de dados, subconjunto PA
a. Crônica de D. João I (Lopes *1380)
b. Crônica Geral de Espanha, títulos 1 a 199 (Espanha) [século XIV] [século XIV]
c. Crônica d'El-Rei D. Afonso Henriques (Galvão *1435) d. Demanda do Santo Graal (Demanda) [século XV] [século XV]

Sobre o conjunto inicial de dados, foram selecionados somente aqueles em que há uma sequência composta por um verbo causativo flexionado (inclusive em um tempo composto) seguido de um verbo infinitivo, a fim de evitar que a mistura de estruturas envolvidas pudesse enviesar os dados. Adotei esse mesmo procedimento de seleção dos dados para o subconjunto relativo aos séculos XVI e XVII, analisado previamente em Trannin (2010), ou seja, procedi à exclusão de:

(i) dados de grupos verbais compostos por mais de dois verbos:

- em que a perífrase causativa está encaixada numa estrutura de "reestruturação" (a podesse [mandar pintar]; ver ANDRADE, 2010 para uma revisão sobre o histórico desse termo);

\footnotetext{
${ }^{4}$ A base de dados referida está disponível na planilha eletrônica em: $<$ https:// dl.dropboxusercontent.com/u/1097038/constr_causativas_pa.xlsx >.
} 
- em que o verbo causativo seleciona um tempo composto (lhe mandava [ter gasalhado]);

(ii) dados em que o verbo causativo está numa forma nãoflexionada (pera o despois mandar fazer);

(iii) dados com o verbo leixar/deixar com uso expletivo, quando acompanhado do clítico reflexivo (deixou-se ficar no covil).

$\mathrm{O}$ uso referido em (iii) se encontra normalmente com um $\mathrm{V}_{\text {inf }}$ intransitivo (mais especificamente inacusativo) e é denominado "uso expletivo" porque o verbo leixar/deixar parece não contribuir para a semântica do enunciado em questão.

Após considerar esses critérios, reclassifiquei os dados de Trannin (2010) seguindo uma metodologia única (explicitada na próxima seção). ${ }^{5}$ O corpus utilizado para os dados do $\mathrm{PCl}$ é arrolado em (9), do qual foram extraídas cerca de 740 sentenças. Todas as obras estão disponíveis no Corpus Tycho Brahe:

(9) Corpus utilizado para a criação da base de dados, subconjunto $\mathrm{PCl}$ a. Peregrinação (Pinto *1510)

[século XVI]

b. Da pintura antiga (Holanda *1517)

[século XVI]

c. Décadas, vol. I (Couto *1542)

[século XVI]

d. A vida de D. Frei Bertolameu dos Mártires (Sousa *1556)

[século XVI]

e. Cortes na aldeia e noites de inverno (Lobo *1579)

[século XVI]

f. Arte de furtar (Costa *1601)

[século XVII]

g. Cartas familiares (Melo *1608)

[século XVII]

h. Cartas, Pe. Antônio Vieira (Vieira/Cartas *1608)

[século XVII]

\footnotetext{
${ }^{5}$ Os dados do $\mathrm{PCl}$, recolhidos no âmbito de pesquisa de mestrado, foram gentilmente cedidos pela autora.
} 
i. História do futuro (Vieira/História *1608)

[século XVII]

j. Sermões, Pe. Antônio Vieira (Vieira/Sermões *1608)

[século XVII]

k. Cartas espirituais (Chagas *1631)

[século XVII]

1. Nova floresta (Bernardes *1644)

[século XVII]

m. Cartas, José da Cunha Brochado (Brochado *1651)

[século XVII]

$\mathrm{n}$. Relação da vida e morte da serva de Deus, a venerável Madre

Helena da Cruz (Céu *1658)

[século XVII]

o. Vida do apostólico Padre Antônio Vieira (Barros *1675)

[século XVII]

p. Regras da língua portuguesa, espelho da língua latina (Argote *1675)

[século XVII]

q. Cartas, Alexandre de Gusmão (Gusmão *1695)

[século XVII]

Nas subseções a seguir apresento a metodologia de classificação dos dados, seguida dos resultados quantitativos e, finalmente, do sumário com o espectro de variação no PA e no PCl.

\subsection{Metodologia de classificação dos dados}

Como já foi dito, no corpus se observam vários dados ambíguos entre diferentes construções, que explicito a seguir. Para tanto, parto das observações feitas na seção anterior, a respeito dos aspectos que diferenciam as construções causativas:

(i) morfologia verbal;

(ii) posição sintática do causado face ao $\mathrm{V}_{\text {inf }}$ e seu valor de caso;

(iii) subida de clíticos (com valor de causado, de arg. int. I ou de arg. int. II). 
Esses critérios permitiram compor uma matriz decisória, que vai dos domínios infinitivos mais "enriquecidos" até os menos "enriquecidos" (ver seção 3), de tal forma a facilitar a classificação dos dados. Com o fito de melhor explicar a metodologia aplicada, divido a matriz decisória em grupos de acordo com o tipo de construção a ser identificada, indico exemplos ilustrativos presentes em outras partes do texto e os critérios envolvidos, e comento os casos à medida em que são apresentados. Os grupos são os seguintes:

- grupo I (10a-b) Infinitivo flexionado;

- grupo II (10c-e) Marcação de caso excepcional;

- grupo III (10f) Infinitivo flexionado ou marcação de caso excepcional;

- grupo IV (10g-h) Fazer-infinitivo;

- grupo V (10i-k) Marcação de caso excepcional ou fazerinfinitivo;

- grupo VI (101-m) Fazer-por.

A título de indicação geral, se o critério em tela não auxilia a identificar uma das construções, o analista deve passar ao próximo, razão pela qual se mantém a mesma numeração - (10) - para indicar todos os grupos que compõem a matriz decisória (as construções são referidas a partir das abreviações 'fazer-Inf', para fazer-infinitivo, 'IF', para infinitivo flexionado e 'MCE', para marcação de caso excepcional; além disso, 'NP' é um sintagma nominal não-pronominal, e 'pré-verbal' sempre se refere à posição do causado face ao $\left.\mathrm{V}_{\text {inf }}\right) \cdot{ }^{6}$

\footnotetext{
${ }^{6}$ Utilizo as abreviações de categorias sintáticas em inglês, como é usual nos trabalhos de sintaxe.
} 
Comecemos pelo grupo I, que envolve a construção de IF:

(10) Matriz decisória, grupo I (IF)
a. O infinitivo é flexionado?
[critério (i)]
Caso positivo, há $\underline{\mathrm{IF}}$
b.O causadoé um pronome nominativo pré-verbal [critério(ii)]
Caso positivo, há IF

O caso em (10a) é obtido se há um morfema número-pessoal visível junto ao infinitivo. Contudo, se o infinitivo tem como causado um pronome nominativo pré-verbal, seu caso só poderá ter sido valorado pelo $\mathrm{V}_{\text {inf }}$ (esses exemplos são enunciados no português europeu somente quando se quer focalizar o pronome; o critério não pode ser estendido ao $\mathrm{PB}$, em que alguns pronomes fortes são usados tanto como sujeito, quanto como objeto): ${ }^{7}$

(11) Ilustração do caso (10b)

O João fez ela ir às compras.

Passemos agora ao grupo II, que envolve a identificação nãoambígua da construção de MCE:

(10) Matriz decisória, grupo II (MCE)

c. O causado é um NP pré-verbal no plural? [critérios (i) e (ii)]

Caso positivo, há MCE

d. Há um pronome alçado acusativo e um

NP pós-verbal, correspondente ao arg. int. I? [critério (ii)]

Caso positivo, há MCE

e. O arg. int. I ou II é

expresso por um pronome não-alçado?

[critério (iii)]

Caso positivo, há MCE

$\rightarrow$ cf. (5a)

\footnotetext{
${ }^{7}$ Alguns dos testes aqui apresentados não podem ser aplicados prima facie à variedade brasileira. Para uma consideração sobre as particularidades do PB, cf. Andrade (2002).
} 
No caso (10c), se o causado é um NP pré-verbal no plural e o infinitivo não apresenta marca de flexão explícita - dado que o analista já passou por (10a) -, há falta de concordância verbal, o causado só pode ter tido seu caso valorado pelo $\mathrm{V}_{\text {caus }}$, ou seja, trata-se de MCE:

Ilustração do caso (10c)

...fizeram todolos Mouros ajuntar-se onde estava o seu pendão (HENRIQUES 231, p. 2, In DAVIES, 1996)

O caso em (10d) enuncia uma situação em que há dois elementos marcados com caso acusativo: um NP pós-verbal, que é valorado pelo $\mathrm{V}_{\text {inf }}$ e um pronome clítico alçado, que só pode ser o causado valorado pelo $\mathrm{V}_{\text {caus }}$. Essa última informação leva a que a construção seja claramente identificada como MCE:

Ilustração do caso (10d)

A todos nos lembra muito bem que o santo mártir apostou contigo que tu à força de tormentos, $\underline{o}$ não farias adorar $\underline{\underline{o s}}$ deuses falsos... (Bernardes *1644)

Já o caso em (10e) está relacionado ao critério relativo à subida de clíticos. Esse fenômeno ocorre obrigatoriamente na construção de "união de orações", mas não na MCE (exceto em (5b), em que não há propriamente subida do clítico, mas sua mera cliticização ao próximo núcleo sintático na estrutura, como já foi mencionado). Isso dito, há evidência fiável de MCE quando há um clítico não-alçado correspondente a um argumento interno do verbo infinitivo, como se indica em (10d). ${ }^{8}$

\footnotetext{
${ }^{8}$ Um critério enunciado por autores como Gonçalves (1999) e que não me parece fiável consiste na existência de uma negação junto ao $V_{\text {inf }}$, pela suposição, muito comum, de que a negação impede a formação de predicados complexos (tanto de "reestruturação" quanto de "união de orações") e, consequentemente, a subida de clíticos. Contra tal generalização observam-se, tanto no $\mathrm{PCl}$, quanto no PEM, exemplos como os seguintes: (i) ... a natural inclinação ... os faz não parar até não chegar ao seu fim último. (Chagas *1631)

(ii) Até te pode não acontecer nada, mas caso aconteça, não tens muito com que provar, entendes? (Disponível em: $<$ forum.zwame.pt/showthread.php?t=551504\&page=54>. Acesso em: 10. Out 2014)
} 
Em seguida, observemos o grupo III, um caso de ambiguidade entre IF e MCE, que surge de uma resposta negativa à pergunta em (10c):

(10) Matriz decisória, grupo III (IF e MCE)

f. Ocausadoé um NPpré-verbal no singular? [critérios(i)e(ii)]

Caso positivo, há ambiguidade IF/MCE $\rightarrow$ cf. (14)

Se não há marca explícita de flexão no infinitivo, a presença de um causado expresso por um NP pré-verbal só nos permitirá afirmar que a sentença é ambígua entre IF e MCE, já que o causado poderá receber caso nominativo ou acusativo, o primeiro valorado pelo $\mathrm{V}_{\text {inf }}$, o segundo, pelo $\mathrm{V}_{\text {caus: }}$ :

(14) Ilustração do caso (10f)

... mandando um Mouro de recado dar aviso aos da forteleza

(Couto *1542 In TRANNIN, 2010).

Em seguida, observemos dois casos de identificação não-ambígua de fazer-Inf, no grupo IV:

(10) Matriz decisória, grupo IV (Fazer-Inf)

g. O causado é um NP pós-verbal marcado com

a preposição $a$, acompanhado de um $V_{\text {inf }}$ transitivo? [critério (ii)]

Caso positivo, há fazer-Inf

h. $O$ causado é um pronome dativo de $3 .^{\text {a }}$ pessoa, acompanhado de um $\mathbf{V}_{\text {inf }}$ transitivo? [critério (ii)] Caso positivo, há fazer-Inf

\footnotetext{
A generalização correta é, portanto, a de que o foco com escopo restrito bloquearia a subida (cf. ANDRADE, 2010); mas, como esse aspecto interpretativo não pode ser depreendido de textos escritos, ele tampouco serve como critério para identificar a construção de MCE.
} 
Os exemplos mencionados ocorrem em sentenças em que o causado é abertamente marcado com caso dativo, o que se expressa inequivocamente, no caso de NPs, pela preposição $a$ em posição pósverbal, e no caso de pronomes, pelas formas de 3 . $^{\text {a }}$ pessoa, em que há formas clíticas privativas para expressar o caso dativo (lhe/lhes).

Observemos agora o grupo $\mathrm{V}$, em que há ambiguidade entre MCE e fazer-infinitivo:

Matriz decisória, grupo V (MCE e Fazer-Inf)

i. O causado é um NP pré-verbal marcado com a preposição $a$ ?

[critério (ii)]

Caso positivo, há ambiguidade MCE/fazer-Inf

j. O causado é um pronome de $1 .{ }^{\mathrm{a}}$ ou de $2 .^{\mathrm{a}}$

pessoa, acompanhado de um Vinf transitivo? [critério (ii)]

Caso positivo, há ambiguidade MCE/fazer-Inf $\rightarrow$ cf.(16)

k. O causado é um pronome acusativo, acompanhado de um Vinf intransitivo?

[critério (ii)]

Caso positivo, há ambiguidade MCE/fazer-Inf

Os dois primeiros casos indicados anteriormente apresentam, de novo, situações em que a ambiguidade surge de uma dupla possibilidade de atribuição de caso ao causado, envolvendo as opções de dativo ou acusativo, o primeiro valorado pelo $\mathrm{V}_{\text {inf }}$, e o segundo, pelo $\mathrm{V}_{\text {caus }}$. Assim, no caso (10i) o NP pré-verbal marcado com a preposição $a$ é ambíguo, já que tal preposição pode ser marcadora de objeto direto preposicionado (ver Differential Object Marking, e.g. em AISSEN, 2003) ou atribuidora de caso dativo:

Ilustração do caso (10i)

Ele faz aos seguos ver e aos surdos ouvir. (José de Arimateia 180r In DAVIES, 1996)

Em (10j), tem-se o caso em que a morfologia pronominal não indica se os pronomes são valorados com caso acusativo ou dativo (morfemas portmanteaux): 


\section{Ilustração do caso (10j)}

Folgara que me mandaram fazer despropósitos toda a vida. (Chagas *1631)

Já no caso (10k), a ambiguidade reside no fato de que tanto o $\mathrm{V}_{\text {caus }}$ quanto o $\mathrm{V}_{\text {inf }}$ atribuem caso com o mesmo valor, acusativo, quando o $V_{\text {inf }}$ é intransitivo (as razões para a diferença de valoração de caso a depender da transitividade do $\mathrm{V}_{\text {inf }}$ serão abordadas na próxima seção):

$$
\begin{aligned}
& \text { Ilustração do caso }(10 k) \\
& \text {... porque a tradição, e a história a fazem renascer a cada } \\
& \text { instante. (Aires } * 1705)
\end{aligned}
$$

Finalmente, consideremos os casos não-ambíguos da construção fazer-por:

(10) Matriz decisória, grupo VI (Fazer-Por)

1. O causado é um NP com caso oblíquo? [critério (ii)]

Caso positivo, há fazer-por

m. O causado não é expresso?

Caso positivo, há fazer-por

O caso descrito em (101) é o mais característico dessa construção, pois o causado ocorre na forma de um NP oblíquo:

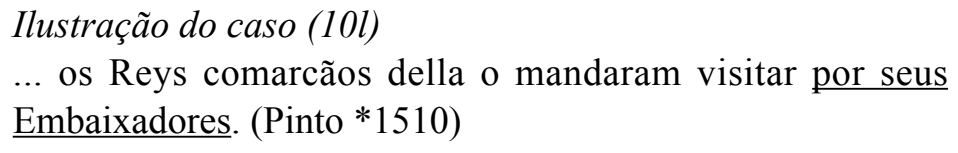

... os Reys comarcãos della o mandaram visitar por seus Embaixadores. (Pinto *1510)

Já o caso (10m) depende da assunção de que, semelhantemente à voz passiva analítica, o oblíquo pode não ser expresso; nesse contexto, o causado deverá ser interpretado como um genérico ou indefinido (ver GUASTI, 2006 e a discussão sobre o exemplo (7) deste texto), como se depreende no caso que segue (em que 'cv' indica categoria vazia):

\section{Ilustração do caso (10m)}

Porém Nero emperador mandou pintar $\left[_{\text {causado }} c v\right]$ em pano um coliseo de CXXI pés. (Holanda *1517) 
Apesar de a lista de possibilidades já parecer bem extensa, ela é a que se infere da leitura dos compêndios gramaticais e de outros textos acadêmicos sobre o assunto. Após a observação de textos antigos, observei mais dois casos de ambiguidade:

- grupo VII (10n) Fazer-por ou marcação de caso excepcional

- grupo VIII (10o) Fazer-infinitivo ou fazer-por

E ainda a necessidade de revisão de um caso que já havia sido enunciado:

- grupo III (10f') Infinitivo flexionado, ou marcação de caso excepcional, ou fazer-infinitivo ou fazer-por

Primeiro, temos que uma análise mais cuidadosa mostrará que o caso enunciado no grupo VII é típico do PA e do $\mathrm{PCl}$ :

(10) Matriz decisória, grupo VII (fazer-por e MCE)

n. O causado não é claramente expresso, e há um clítico alçado, acompanhado de um Vinf com valência variável? [critério extra]

Caso positivo, há ambiguidade fazer-por/MCE $\rightarrow$ cf.(20)

O caso (10n) corresponde a verbos que se alternam entre dois padrões de valência, transitivo e intransitivo, estando a ambiguidade presente nessa última propriedade. Assim, no exemplo (20), há duas interpretações: uma em que o verbo é transitivo, e o causado é um elemento não-expresso na sintaxe, com valor semântico indefinido ( 'fizeram com que [alguém] nos desarmasse logo'); e outra em que o verbo é intransitivo, e o causado é expresso pelo clítico alçado, que acumula a função de clítico inerente ( 'fizeram com que nós nos desarmássemos logo'). Em outras palavras, nesse último caso o causado e o elemento inerente apresentam um único expoente na morfologia: na interpretação transitiva do verbo, há fazer-por, semelhantemente ao caso (101); e na interpretação intransitiva, há MCE. ${ }^{9} \mathrm{Na}$ primeira, o clítico

\footnotetext{
${ }^{9}$ Acredito que a maior ambiguidade no $\mathrm{PA}$ e $\mathrm{PCl}$ advém do fato de a segunda leitura ser, hoje em dia, preferencialmente expressa como na paráfrase indicada no texto (com a
} 
receberia acusativo de $\mathrm{V}_{\text {inf }}$; na segunda, de $\mathrm{V}_{\text {caus }}$ :

(20) Ilustração do caso (10n)

E fezeromnos desarmar logo... (Demanda 506, 164b)

Segundo, temos o caso em que há um clítico dativo alçado:

(10) Matriz decisória, grupo VIII (Fazer-Inf e fazer-por)

o. O causado não é claramente expresso, e há um pronome dativo alçado? [critério extra]

Caso positivo, há ambiguidade fazer-Inf/fazer-por $\rightarrow$ cf.(21)

$\mathrm{Na}$ ilustração, observa-se que outra possibilidade advinda do sistema deriva de um clítico dativo poder ser interpretado como causado, quando se tem a interpretação de fazer-por; ou como arg. int. II do $\mathrm{V}_{\text {inf' }}$, quando se tem a interpretação de fazer-Inf:

(21) Ilustração do caso (10o)

El-rei fez fihar Erec e fez-lhe tam gram honra fazer como devia a filho de rei e a tam boo cavaleiro como el fôra. (Demanda $356,117 \mathrm{a})$

Passo agora ao caso que foi revisto. Considero que, especificamente para o PA (portanto, sem incluir o $\mathrm{PCl}$ e o PEM), pode-se apontar que uma variante do caso (10f) envolve uma ambiguidade ainda maior, entre IF, MCE e fazer-Inf ou fazer-por:

(10) Matriz decisória, grupo III, revisado para o PA (IF, MCE e fazer-Inf ou fazer-por)

f'. O causado não é claramente expresso;

o $\mathrm{V}_{\text {inf }}$ é intransitivo, e há um NP pré-verbal no singular? [critério extra]

expressão fazer com que seguida de oração subjuntiva), pois ainda não tinha observado exemplos similares a (20) em dados do PB ou PEM. Nessa segunda interpretação a sequência nos nos seria barrada pelo Princípio do Contorno Obrigatório (OCP em inglês), havendo diferentes abordagens teóricas para sua derivação na morfologia (cf. NEVINS, 2007). 
Caso positivo, há ambiguidade IF/MCE/fazer-Inf (ou fazerpor)

A razão para se ampliar esse caso de ambiguidade tem a ver com a observação do fenômeno de scrambling ("embaralhamento", em português) de curta distância, que envolve um movimento estilístico do argumento interno para a posição anterior ao $\mathrm{V}_{\text {inf }}$ (mais detalhes sobre essa estrutura são apresentados na seção 3.1). ${ }^{10}$ No exemplo a seguir, tendo em vista que o $\mathrm{V}_{\text {inf }}$ é intransitivo, o sintagma sa lança poderia receber: nominativo de $\mathrm{V}_{\text {inf }}$ (IF); acusativo de $\mathrm{V}_{\text {caus }}$ (MCE); ou acusativo de $\mathrm{V}_{\text {inf }}$ (fazer-Inf), com a assunção de que o argumento sofreu scrambling:

(22) Ilustração do caso (10f') com ambiguidade entre IF, MCE e fazer-Inf

E Sagramor fez sa lança voar em peças $(G 336,111$ c)

Dois exemplos com $\mathrm{V}_{\text {inf }}$ transitivos oferecem evidência crucial para se compreender o envolvimento do scrambling de curta distância para desfazer a ambiguidade, ou seja, a única interpretação possível é aquela em que o elemento em posição interverbal recebe caso acusativo ou dativo do $\mathrm{V}_{\text {inf: }}{ }^{11}$

(23) Ilustração do caso (10f'), em que a ambiguidade é desfeita a favor da interpretação de fazer-por ou fazer-Inf, com scrambling de curta distância

a. E os senadores mandaron logo esto dizer ao emperador Justinyano. (Espanha 119, 46b)

b. E enton o fez a todos chamar rey. (Espanha 108, 42c)

\footnotetext{
${ }^{10}$ Essa posição poderia ser identificada, para os que defendem a proposta cartográfica de derivação, com um foco baixo na periferia do $v$ P (cf. BELLETTI, 2004). Para Martins (2002), o PA apresentaria um scrambling de média distância (em adjunção a TP).

${ }^{11}$ Na posição interverbal também pode ocorrer o causador, um tipo de inversão sujeito-verbo:

(i) ... e mandoulhe o Arcebispo dar a elles, e aos seus todas as cousas que lhe mester faziaõ... (Lopes *1380, 102)
} 
Em (23a) o NP esto só pode ser interpretado como o arg. int. I do $\mathrm{V}_{\text {inf }}$ dizer (sendo o arg. int. II o PP ao emperador Justinyano); nesse exemplo o causado não é expresso, e estamos diante de um caso nãoambíguo de fazer-por. A sentença (23b) é um pouco mais complicada, pois ocorre como $\mathrm{V}_{\text {inf }} \mathrm{o}$ verbo de denominação chamar, que apresenta uma estrutura argumental com uma predicação secundária entre o designando e a designação, com a seguinte interpretação no contexto (desfazendo a subida do clítico): [O rei Teuderigo] fez chamá-lo [=o seu neto Amalarico] rei a todos, em que -lo é o designando, rei é a designação, e $a$ todos é o causado. ${ }^{12}$ De fato, a subida do clítico $o$ argumento interno já é evidência suficiente de estarmos diante de um caso de "união de orações", mais especificamente do tipo fazer-Inf, pois nesse caso $a$ todos só pode ter sido valorado com caso dativo pelo $\mathrm{V}_{\text {inf }}$, e não com caso acusativo (preposicionado) pelo $\mathrm{V}_{\text {caus }}$. Nesses dois exemplos, notase que argumentos cuja posição natural (a partir do português atual) seria pós-verbal (ou seja, pós- $V_{\text {inf }}$ ), por receberem caso do infinitivo, ocorrem antes dele. Nos dois casos apontados anteriormente, é crucial que o analista tenha em conta que era uma característica do PA e do PCl (pelo menos até meados do século XVI) a possibilidade de interrupção da adjacência entre $V_{\text {caus }}$ e $V_{\text {inf }}$ por um advérbio ou um sujeito invertido (ver TRANNIN, 2010, p. 58, e (23a), que combina dois elementos), diferentemente do PEM.

Finalmente, uma ressalva. Um possível questionamento da análise apresentada refere-se ao caso $(10 \mathrm{~m})$, em face da aplicabilidade da análise de Guasti (2006) para os dados do português. Segundo essa ideia, o causado seria projetado na sintaxe, porém realizado como uma categoria vazia em posição argumental, sendo valorada com acusativo pelo $\mathrm{V}_{\text {causs }}$, como um objeto nulo. Essa interpretação levaria a que houvesse mais um caso de ambiguidade entre fazer-por e MCE, porém ela não parece ser correta, pois:

(i) objetos nulos ocorrem claramente somente em dados do PEM;

(ii) uma segunda interpretação, específica para o causado, deveria estar disponível.

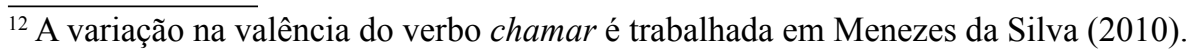


Apesar de não concordar com esse critério de ambiguidade, separar tais dados pode ser útil para identificar os casos de "união de orações" (de tipo fazer-por) assim classificados por apresentarem um causado não-expresso. Identificarei eventualmente esses casos com o rótulo União de Orações [-CAUSADO].

Além de observar os pontos em que há ambiguidade, é relevante apontar a importância relativa desses critérios. Acredito, de fato, que a maior parte dos casos encontrados no corpus pode ser analisada com os oito grupos de critérios elencados. ${ }^{13}$ Para apontar a relevância dos critérios, apliquei-os aos dados do século $\mathrm{XV}$, com a seguinte distribuição:

${ }^{13} \mathrm{O}$ leitor pode se questionar quanto ao impacto que a matriz decisória aqui proposta teve sobre a reclassificação dos dados de Trannin (2010). Houve concordância na classificação da maior parte dos casos, exceto dois maiores casos de discordância derivados de análise sobre questões sintáticas mais específicas ('PS' indica Predicado Secundário):

(i) Construção: predicado secundário com NP ou clítico arg. int. alçado ... eu confesso a culpa de não aplicar o que disse à vossa graça e galantaria, que é o sal com que vos convidei, e que a [tôdas as práticas desta nossa conversação] ${ }_{i}$ faz parecer $\left[\mathrm{PS}_{\mathrm{PV}} \mathrm{Cv}_{i}\right.$ agradáveis e saborosas] a todo o entendimento. (Lobo *1579) a. Análise original: o elemento recebe acusativo do $\mathrm{V}_{\text {caus }}$ (de outro forma não poderia ter sofrido movimento-A), portanto há MCE.

b. Análise revisada: o elemento pode receber acusativo do $\mathrm{V}_{\text {caus }}$ ou do $\mathrm{V}_{\text {inf }}$, sendo que, no último caso, sofreu movimento-A' (por topicalização ou focalização), portanto há ambiguidade entre MCE e fazer-Inf.

(ii) Construção: clítico $s e$ indefinido, com sujeito nulo

... e assi ficava ardendo em mais secura, porque a pouca água que tomava era provocadora de mais sede, como se deixa entender em boa filosofia. (Sousa *1556)

a. Análise original: o clítico tem caso acusativo valorado pelo $\mathrm{V}_{\mathrm{inf}}$ e foi alçado; portanto, há fazer- Inf.

b. Análise revisada: o clítico é gerado numa posição no domínio do $\mathrm{V}_{\text {caus }}$, ou seja, pode ocorrer uma subida de clíticos espúria; portanto, há ambiguidade entre MCE e fazer-inf.

Uma evidência para a análise revisada no caso (ii) é a possibilidade de construção semelhante no $\mathrm{PB}$, que usualmente não tolera a subida de clíticos:

(iii) Um homem desses não se pode esquecer. (MONTEIRO, 1991. In GALVES; ABAURRE, 1996, p. 306) 
(24) Distribuição aproximada dos casos de ambiguidade nos textos do $P A$
a. Grupo III, (10f')
média
$15 / 138(10 \%)$
b. Grupo V, (10i)
baixa
$1 / 138(<1 \%)$
c. Grupo V, $(10 \mathrm{j})$
alta
$52 / 138(52 \%)$
d. Grupo V, (10k)
alta
$52 / 138(52 \%)$
f. Grupo VII, (10n)
baixa
$3 / 138(2 \%)$
e. Grupo VIII, (10o)
média

Com base nessa varredura de possibilidades de classificação das construções, cheguei à conclusão de que a base de dados seria melhor analisada a partir da classificação quanto aos critérios mostrados na Tabela 2, em que: o item $a$ serve inicialmente para controle; os itens $b-d$ são auxiliares para a identificação de construções; e os itens $e-f$ são caracterizadores das construções (ou ambiguidades) em dois níveis. O nível mais alto, o tipo de construção causativa (item f.), foi o item determinante para a análise desenvolvida na próxima seção. Já num nível menor, tem-se a classificação entre os subtipos de "união de orações" (item e.).

Tabela 2 - Critérios de classificação da base de dados

\begin{tabular}{|c|c|c|}
\hline Item & Critério & Fatores \\
\hline a. & $\mathrm{V}_{\text {caus }}$ & - fazer, deixar, mandar; \\
\hline b. & Causado & - pronome, NP, PP, zero; \\
\hline c. & Elemento interveniente & $\begin{array}{l}\text { - NP-causador, NP-causado, } \\
\text { NP-arg. int., PP-oblíquo, PP- } \\
\text { adjunto, AdvP, zero; }\end{array}$ \\
\hline d. & Clítico & $\begin{array}{l}\text { - causado, arg. int. I, arg. int. II, } \\
\text { contraído, possessivo, passivo/ } \\
\text { reflexivo, inerente, ambíguo, } \\
\text { zero; }\end{array}$ \\
\hline e. & "União de orações" & $\begin{array}{l}\text { - Fazer-Inf, fazer-por, ambígua } \\
\text { fazer-Inf/fazer-por; }\end{array}$ \\
\hline f. & Construção causativa & $\begin{array}{l}\text { - IF, MCE, "união de orações", } \\
\text { a mbígua MCE/ "união", } \\
\text { ambígua IF/MCE. }\end{array}$ \\
\hline
\end{tabular}

Note-se que, como Trannin (2010) não havia trabalhado com dados do PA, a reclassificação não tem impacto sobre a identificação da emergência da marcação de caso excepcional, que aparece já no século XV. 
Na averiguação dos resultados quantitativos, considero os seguintes princípios de identificação de construções sintáticas, considerando ainda que, para os fins desta pesquisa, o comando em (25a) é suficiente: ${ }^{14}$

(25) Princípios de identificação de construções sintáticas

a. Postule a existência de uma construção numa determinada gramática se e somente se pelo menos um caso não-ambíguo for identificado.

b. Verifique a existência de casos de extensão ou gramaticalização em curso, caso a construção ocorra em menos de $5 \%$ dos casos (excluindo-se os casos de ambiguidade).

\subsection{Resultados empíricos: a distribuição da marcação de caso excepcional}

Apresento, a seguir, os dados das construções, encontradas em cada um dos subconjuntos de dados:

(i) séculos XIV e XV, considerados parte do PA;

(ii) séculos XVI e XVII, considerados parte do PCl.

O uso de números absolutos será privilegiado, num primeiro momento, já que o que está em causa é o aparecimento de dados de uma construção específica, MCE, e não tanto a proporção relativa entre as construções em tela. Dado esse enfoque, deixarei a discussão sobre os dados de infinitivo flexionado para a seção 2.3.

A base de dados do PA apresentou, em sua maior parte, dados de "união de orações"; uma quantidade menor de dados inclui casos ambíguos; e somente 3 dados foram classificados claramente como casos de marcação de caso excepcional. Tais resultados são resumidos na Figura 1 (os valores exatos, na ordem das construções citadas na figura, são: para o séc. XIV - deixar 9/10/2; fazer 114/23/0; mandar 133/7/0); para o séc. XV - deixar 13/50/0; fazer 148/87/1; mandar 34/8/0).

\footnotetext{
${ }^{14} \mathrm{O}$ valor de $5 \%$ em (25b) se baseia num nível usual de significância estatística $(\mathrm{p}<0,05)$.
} 


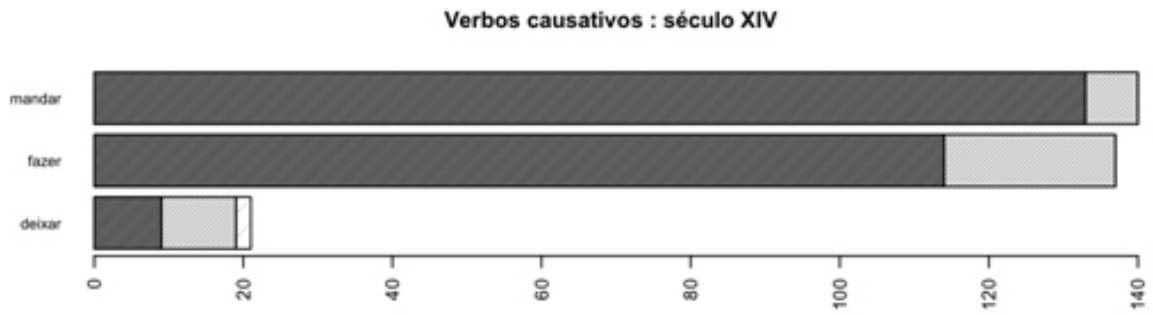

Verbos causativos : século XV

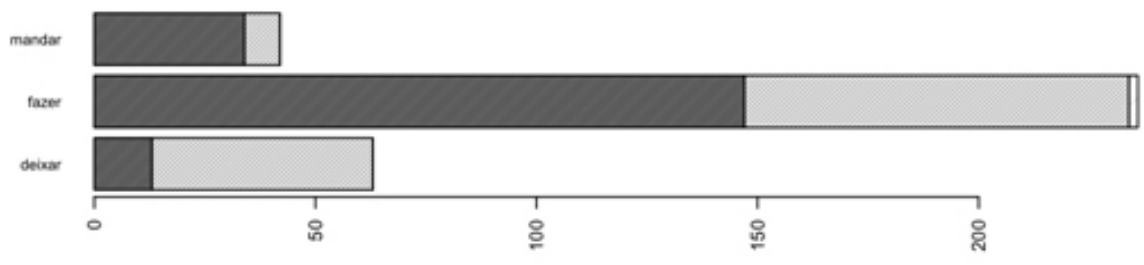

Figura 1 - Dados absolutos por tipo de verbo e construção causativa (sécs. XIV e XV)

A construção de MCE aparece mais claramente no segundo conjunto de dados, relativos ao $\mathrm{PCl}$ : 11 dados não-ambíguos no século XVI e 27, no século XVII. Os resultados obtidos da quantificação dos dados do $\mathrm{PCl}$ são mostrados na Figura 2 (os valores exatos, na ordem das construções citadas na figura, são: para o séc. XVI - deixar 21/10/1; fazer 51/16/8; mandar 223/13/4; para o século XVII - deixar 43/26/8, fazer $83 / 35 / 11$; mandar $148 / 22 / 8$ ). 

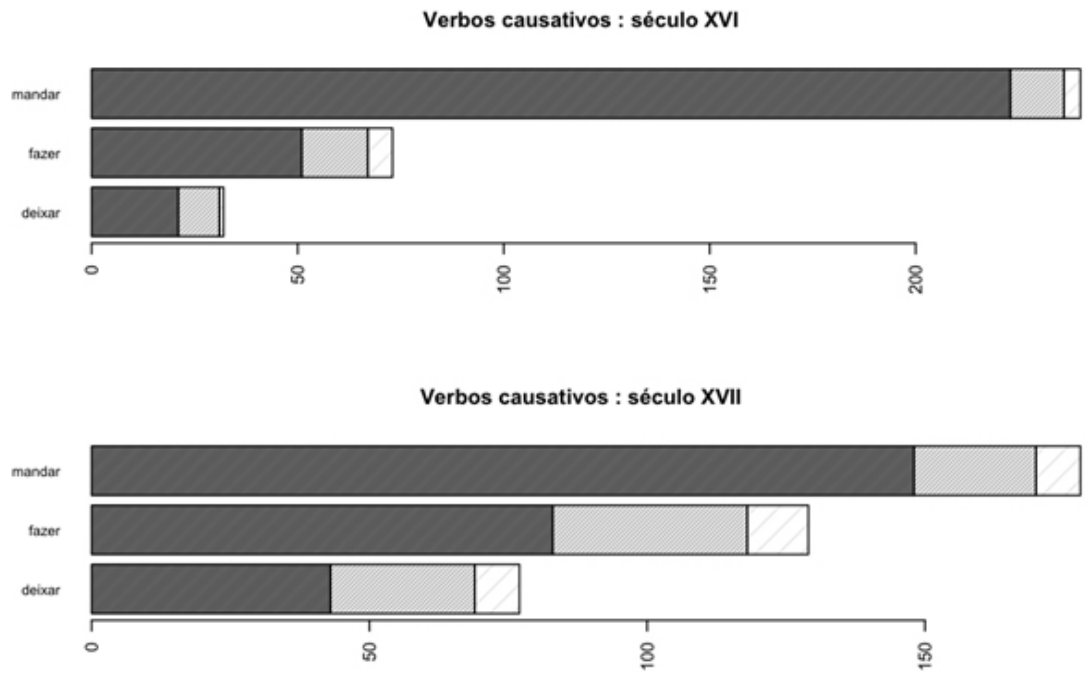

Figura 2 - Dados absolutos por tipo de verbo e construção causativa (sécs. XVI e XVII)

No PA, encontram-se somente duas suspeitas de dados de MCE no século XIV e uma no século XV; aqueles com leixar/deixar e este com fazer:

(26) Casos suspeitos de marcação de caso excepcional nos dados do PA a. ... e por esto foy rogar aos samcristããos da igreja de Sam Pedro que o leixassem tẽẽr vigilia em aquella igreja. (Espanha $150,155 b)$

b. E os da hoste pedyron a el rey que os $\overline{\text { leixasse }}$ tomar aver daquelles castellos. (Espanha 160, 60b)

c. Era para louvar a Deus, e folgar de ver o esforçado pelejar dos nossos, que por força fizeram juntar-se onde estava o pendão de Sevilha. (Galvão*1435, 66)

As sentenças em (26a-b) foram identificadas como exemplos de MCE pelo caso (10d), já que há um clítico acusativo alçado e um NP 
acusativo após o $\mathrm{V}_{\text {inf }}$ Já (26c) foi identificada pelo caso (10c), dado o clítico (com valor recíproco) não-alçado. Apesar de tais exemplos, ainda acredito ser possível afirmar que a construção de MCE não era produzida pela gramática do PA. Analiso os casos encontrados nos séculos XIV e $\mathrm{XV}$, separadamente, a seguir.

Os dados do século XIV (26a-b) ocorrem com o verbo causativo leixar/deixar, que é semanticamente bastante distinto dos demais verbos que participam de construções causativas perifrásticas. Note-se, primeiro, que o preenchimento da posição interverbal pelo causado (ordem VOV) no PEM está ligada a uma maior topicalidade ou agentividade atribuída ao causado, no âmbito do domínio infinitivo, com consequência sobre a relação causador-causado; assim, em (27a) o causador a Maria é percebido em relação direta com o causado $o$ João, enquanto em (27b) a Maria se coloca em relação direta com o evento descrito no domínio infinitivo (ver SOARES DA SILVA, 2005, sobre a semântica dessas construções):

a. A Maria fez o João trabalhar.

b. A Maria fez trabalhar o João.

O verbo leixar/deixar constrói uma construção causativa permissiva em que a maior topicalidade ou agentividade do causado não advém da sintaxe, mas de uma característica lexical: esse verbo sempre atribui uma maior topicalidade ou agentividade ao causado. Isso pode explicar por que, em francês, laisser ('deixar') permite o causado em posição interverbal, diferentemente de faire ('fazer'), como mostra o seguinte par de sentenças (exemplos de ACHARD, 1998, p. 73-74):
a. * Marie fait Jean pleurer.
'A Marie faz o Jean chorar.'
b. Marie laisse Jean pleurer.
'A Marie deixa o Jean chorar.'

Interpreto, portanto, que as ocorrências da ordem VOV nos dados (26a-b) são semelhantes ao exemplo (28a), sendo portanto casos espúrios de MCE, deixando uma análise mais pormenorizada sobre essa decisão 
para a seção 3.2, uma vez que ela depende da compreensão específica da estrutura envolvida.

Quanto ao exemplo do século XV (26c), avalio-o como um caso real de MCE, que deriva não só da não-subida do clítico, mas sobretudo da sua semântica como recíproco, da qual se infere uma referência específica ao causado (não claramente expresso) no exemplo em tela. Nessa altura, recupero a ressalva feita logo acima do exemplo (24), em que mencionei a possível utilidade de se separarem, do total de dados de "união de orações", aqueles assim classificados por não apresentarem um causado expresso (correspondentes à construção fazer-por). Em outras palavras, esse tipo de exemplo aponta para uma alta frequência de causados não-expressos nos dados do PA.

Essas observações me levam a apresentar outro conjunto de dados na Figura 3, que exclui os dados com o verbo causativo permissivo leixar/ deixar e, ao mesmo tempo, separa os dados de "união de orações" com causado não-expresso [-CAUSADO] daqueles que com um causado expresso [+CAUSADO]. Nessa figura, fica claro que a construção de MCE vai ganhando terreno progressivamente a partir do século XV $(0,0 \% ; 0,7 \%$; $3,2 \% ; 6,2 \%)$. Os dados também demonstram que a quantidade de dados ambíguos é variável, podendo atingir mais de $30 \%$, não se distinguindo uma tendência de redução da ambiguidade $(10,4 ; 33,8 \% ; 9,3 \% ; 18,6 \%)$. O segmento de dados União de Orações [-CAUSADO] chama a atenção por ser o mais numeroso em cada século, chegando a quase três quartos no século XIV, resultado que pode ser atribuído ao estilo das crônicas reais, em que usualmente o que está em relevo é o causador (“o rei") e o objeto da ação comandada, e ficando em segundo plano o causado ("servo ou súdito") $(71,2 \% ; 41,4 \% ; 65,8 \% ; 45,6 \%)$. Finalmente, os dados de União de orações [+CAUSADO] mantêm-se num patamar relativamente estável, em torno de $20 \%(18,4 \% ; 24,1 \% ; 21,7 \% ; 29,6 \%)$. 


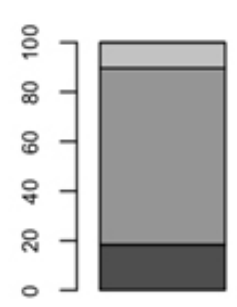

XIV

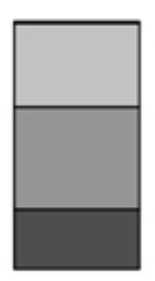

$\mathrm{XV}$

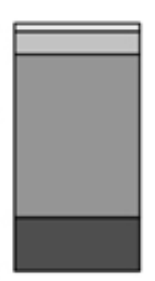

$\mathrm{XVI}$

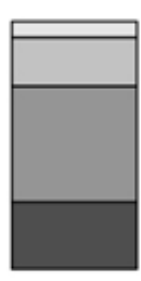

XVII
- Uniâo de Oraçóes [+CAUSADO]

口 Uniáo de Oraçóes [-CAUSADO]

C Casos ambiguos

Marcaçăo de Caso Excepcional

Figura 3 - Percentagens de construções causativas factitivas (excluindo deixar) por século

Os resultados da figura 3 também são relevantes para mostrar que somente a grande quantidade de dados ambíguos não é capaz de explicar a falta de dados de MCE no PA. Uma possível crítica aos resultados iria no sentido de dizer que dados não-ambíguos dessa construção não ocorrem no século XIV como uma consequência da grande quantidade de dados com causado não-expresso. No entanto, se isso fosse verdade, esperaríamos o mesmo resultado no século XVI, que tem uma percentagem semelhante desse tipo de dado, mas em que 11 dados puderam ser claramente identificados.

Para desvendar a relação entre a expressão do causado e a identificação das construções causativas, no entanto, é necessário fazer um explicação de fundo sobre a arquitetura da gramática do português antigo. Antes disso, passo a um sumário dos resultados empíricos alcançados, incorporando aqueles relativos ao infinitivo flexionado.

\subsection{Sumário dos resultados empíricos}

Na seção anterior, vimos que só um caso inequívoco de MCE foi observado nos dados dos séculos XIV e XV. No entanto, a ocorrência de um único exemplo não infirma a hipótese apresentada no começo deste trabalho, pois o texto em questão foi produzido na segunda metade do século $\mathrm{XV}$, momento que se situa já no começo do $\mathrm{PCl}$, segundo a proposta de periodização de Galves, Namiuti e Paixão de Sousa (2006). Ao mesmo tempo, esse dado mostra que (26c) seria o indício da emergência da construção de MCE na história do português, situada já na transição para o $\mathrm{PCl}$.

O princípio em (25a) também é suficiente para afirmar que a construção de infinitivo flexionado não estava disponível no complemento de verbos causativos, nem na gramática do PA, nem 
na do $\mathrm{PCl}$, já que nenhum dado não-ambíguo dessa construção foi identificado na base de dados. Por outro lado, com respeito aos dados ambíguos entre IF e outras construções, não há nenhum no século XIV, há três no século XV - cf. $(29 \mathrm{a}-\mathrm{c})-$, nenhum no século XVI, e um no século XVII - cf. (29d):

(29) Dados ambiguos entre IF, MCE (e Fazer-Inf)

a. E, depois que esto disse, foi depós a besta e leixou Glifet jazer em terra. (Demanda 101, 33c)

b. Tornemos nos per u saimos e veemos se poderiamos achar o treedor de Galvam, que leixou meu irmão morrer per sua covardice. (Demanda 137, 45b)

c. Ele a firiu tam rijamente que 1[e] fez a cabeça caer mais longe de ũa lança e o corpu caiu em terra. (Demanda 296, 105d)

d. Ao exemplo se diz, que naõ se deixou a Infanta Dona Violante herdar naõ pornaõ se admittir á representaçaõ no caso, senaõ por ser inhabil por ley particular... (Costa *1601)

Sobre (29a-c), evoco o caso (10f') (para o PA), dada a possibilidade de análise dos NPs sublinhados como objetos da operação de scrambling, o que torna tais exemplos triplamente ambíguos, impedindo que ocorresse a reanálise para a construção de MCE e tampouco para a construção de IF. Destarte, as construções causativas se distribuiriam no português diacrônico conforme se mostra na Tabela 3 .

Tabela 3 - Construções causativas em variedades diacrônicas do português

\begin{tabular}{l|ll}
\hline Construção/Gramática & PA & PCI \\
\hline Fazer-infinitivo & $\checkmark$ & $\checkmark$ \\
Fazer-por & $\checkmark$ & $\checkmark$ \\
Marcação de caso excepcional & $\mathbf{x}$ & $\checkmark$ \\
Infinitivo flexionado & $\mathbf{x}$ & $\mathbf{x}$ \\
\hline
\end{tabular}

\section{Análise formal, parte I: os verbos causativos e a gramática do português antigo}

Nesta seção, apresento uma explicação para a obrigatoriedade da formação de predicados complexos (expressos pela construção de "união de orações", de fazer-infinitivo ou fazer-por) no PA. Para tanto, 
apresento: em 3.1, uma visão geral sobre uma versão da teoria de parâmetros, desenvolvida em Roberts (2010b); em 3.2, uma explicação sobre o parâmetro de alinhamento de argumentos e sua relação com a "união de orações" no PA; em 3.3, o parâmetro de configuracionalidade discursiva e o scrambling.

A teoria de parâmetros aqui desenvolvida é modelada no âmbito do programa minimalista que, em suas versões mais recentes adota, entre outros pressupostos, a existência da operação Mover como resultado da conjunção entre duas outras operações: Concordar e Arrastar (Agree e Pied-Piping; ver CHOMSKY, 2001; 2008). Para que ocorra Concordar, é necessária a presença de pares de traços: não-interpretável e interpretável, o primeiro efetuando sua valoração com o segundo. Por exemplo, na base de uma representação arbórea, um argumento interno tem traços de gênero, número e pessoa interpretáveis (traços-phi), mas necessita de Caso, que será valorado como acusativo pelo núcleo $v$, que é o primeiro elemento com traços-phi não-interpretáveis $([u / p h i])$. O processo de valoração é exemplificado a seguir, em que $v$ é a sonda, que busca os traços interpretáveis no alvo, o NP argumento interno:

(30) Arranjos de traços antes e depois da operação Concordar

a. Sonda $=v$ [Pessoa: ; Número: ] $\ldots$ Alvo $=\mathrm{NP} / \mathrm{phi}$ [Pessoa: $a$; Número: $b$ ]

b. Sonda $=v[$ Pessoa: $a$; Número: $b] \quad \ldots$ Alvo $=\mathrm{NP} / \mathrm{phi}$ [Pessoa: $a$; Número: $b$ ]

Em (30a), o núcleo $v$ não tem traços de pessoa e número, mas adquire-os por meio da operação Concordar, com o resultado em (30b). A operação Arrastar ocorrerá, a depender da língua, por conta da existência de um diacrítico de movimento $\left({ }^{\wedge}\right)$ junto aos traços-phi não-interpretáveis $[\mathrm{u} / \mathrm{phi}, \wedge]$, movendo, assim, o NP envolvido em Concordar para Spec, $\nu \mathrm{P}$. Crucialmente, se o argumento interno é um pronome clítico, ele não projeta um sintagma, sendo puramente um conjunto de traços-phi e movendo-se para o núcleo com o qual concorda independentemente da presença do diacrítico de movimento (cf. a noção de alvo defectivo em ROBERTS, 2010a).

A operação Mover não ocorre livremente, mas se restringe ao âmbito de fases sintáticas. As fases são marcadores sintagmáticos que contêm um núcleo de fase e um traço de borda (edgefeature, ou [u/edge]), 
capaz de fazer certos elementos se moverem para o domínio superior por meio de uma válvula de escape (escape hatch), se tiverem um diacrítico de movimento $\left(^{\wedge}\right)$ (BIBERAUER; HOLMBERG; ROBERTS, 2010). Quando a operação Transferir se aplica ao complemento do núcleo de cada uma das fases sintáticas, ela envia o material ali contido para as interfaces da sintaxe com os sistemas conceitual-intencional e sensóriomotor. Ou seja, somente o núcleo da fase e o elemento que está em sua borda (edge) ficam disponíveis para sofrer novas operações. Considero, seguindo Roberts (2010b), que os núcleos de fase são $C$, Voice e $D$. Dessa forma, seus complementos são demarcados, respectivamente, ao lado direito das barras '/' na seguinte representação:

$$
\left[{ }_{\mathrm{CP}} \underline{\mathrm{C}} /\left[_{\mathrm{TP}} \mathrm{T}\left[_{\text {VoiceP }} \underline{\text { Voice }} /\left[_{\nu \mathrm{P}} \mathrm{V}\left[_{\mathrm{RootP}} \operatorname{Root}\left[{ }_{\mathrm{DP}} \underline{\mathrm{D}} /\left[_{\text {PossP }} \cdots\right]\right]\right]\right]\right]\right]\right]
$$

Em (31) mostra-se que há um núcleo que abriga a raiz de uma categoria lexical, Root, que se torna um verbo por movimento para o próximo núcleo de sintagma, $v$. Na proposta de Chomsky (2008) se explicita que todo movimento tem origem nos núcleos de fase: assim, mesmo os traços [u/phi] em $\mathrm{T}$ e em $v$ são resultado da operação Doar, partindo respectivamente de $\mathrm{C}$ e de Voice.

\subsection{Os sistemas de parâmetros e a diacronia}

O sistema descrito anteriormente seria geral para as línguas do mundo, sendo a variação nos parâmetros responsável pelos diferentes tipos de línguas. Roberts (2010b) propõe a existência de parâmetros atuando tanto na Forma Fonética quanto na Sintaxe Estrita, que seriam distinguíveis em termos da presença de uma lacuna no espaço lógico de possibilidades, no caso do segundo tipo de parâmetros. Um exemplo do primeiro fenômeno diz respeito às marcas entre núcleo e complemento na morfologia, que podem se externalizar: no núcleo; no seu complemento; em ambos os núcleos; ou em nenhum dos dois. No caso do segundo fenômeno, o autor menciona a linearização, que parece não permitir a ordem "núcleo final-núcleo inicial” (numa sequência de dois sintagmas) mas aceita as três outras combinações possíveis: "núcleo final-núcleo final"; "núcleo inicial-núcleo inicial"; "núcleo inicial-núcleo final". 
Essas possibilidades se organizam em termos da noção de marcação (markedness), definida por meio da dificuldade de aprendizagem, como em (32). Considerando ainda que a realização da operação Mover é de último recurso (só ocorre quando for preciso), obtém-se uma hierarquia de opções, como se mostra em (33) (exemplos de ROBERTS, 2010b, traduzidos e adaptados).

\section{Convenção de marcação}

Para uma classe de núcleos $\mathrm{N} \neq$ Voice, o valor não-marcado para o diacrítico de movimento será [+movimento] se Voice é [+movimento] e [-movimento] em todos os outros casos.
Hierarquia de marcação
a. final-final $>$ inicial-final $>$ inicial-inicial
b. inicial-inicial $>$ inicial-final $>$ final-final

A convenção de marcação em (32), derivada de uma tendência de generalização do aprendiz de língua, prevê duas possíveis hierarquias: (33a), caso o movimento seja marcado; e (33b), caso o movimento seja não-marcado. ${ }^{15}$ Isso prediz duas coisas:

(i) uma hierarquia pode ser didaticamente apresentada num esquema semelhante a uma árvore de decisões, sendo que o parâmetro situado no topo é um macroparâmetro, ou seja, uma decisão que divide as línguas do mundo entre opções muito distantes, e quanto mais encaixado é o parâmetro em tela, mais marcadas e menores são as diferenças em jogo;

(ii) no âmbito da diacronia, a deriva tipológica esperada (drift) vai no sentido de uma mudança para cima.

No entanto, aparentes mudanças para baixo são possíveis ao se inverter a convenção de marcação em (32), por pressões das interfaces com a sintaxe.

Roberts (2010b) menciona a existência de cinco hierarquias de parâmetros:

\footnotetext{
${ }^{15}$ Considerando a teoria de Kayne (1994), para quem a ordem núcleo-final é obtida por movimento do complemento, o que Biberauer, Holmberg e Roberts (2010) denominam movimento de linearização, ligado a um traço de seleção categorial.
} 
- ordem de palavras (linearização);

- argumentos nulos;

- estrutura da palavra;

- configuracionalidade discursiva;

- alinhamento morfossintático.

Quando se comparam duas línguas ou estágios de uma mesma língua histórica, é importante ter em mente que pode haver grande proximidade com relação a uma hierarquia, mas distância no que se refere a outra. Para este trabalho, darei enfoque às duas últimas hierarquias citadas, das quais passo a tratar a seguir.

\subsection{O parâmetro do alinhamento morfossintático e a "união de orações"}

O alinhamento morfossintático é um critério bastante eficaz para a tipologia linguística, podendo ser entendido como a forma como o objeto (O), o sujeito de um verbo transitivo (A) e o sujeito de um verbo intransitivo (S) são marcados. Há diferentes possibilidades, porém a divisão clássica separa dois sistemas:

- direto: acusativo-nominativo ( $\mathrm{S}=\mathrm{A}$; $\mathrm{O}$ é diferente);

- inverso: ergativo-absolutivo ( $\mathrm{S}=\mathrm{O}$; A é diferente).

Uma mesma língua pode, no entanto, ser mista, apresentando os dois sistemas em contextos diferentes. De fato, a ergatividade morfológica se expressa normalmente em contextos encaixados, nos quais originalmente há uma relação diacrônica com uma nominalização (isso expressa o fato de o alinhamento inverso ser no geral mais marcado que o alinhamento direto). No caso das construções causativas, a construção de "união de orações" expressa um alinhamento inverso, como se nota a partir do paralelo com o alinhamento de argumentos numa nominalização:
a. Ele fez escrever o trabalho (pelo João).
b. Ele fez sair o João.
a. A escrita do trabalho (pelo João).
b. A saída do João.

Nos exemplos acima, S ( o João, sujeito do verbo intransitivo sair) 
está alinhado com O (o trabalho, objeto do verbo transitivo escrever).

Os diferentes tipos de construções causativas apresentadas em (1) devem, portanto, exprimir essa divisão básica entre alinhamentos direto e inverso. Para tanto, a operação Mover não é suficiente, já que há quatro opções em jogo; assim, considero, juntamente com Wurmbrand (2003), que a estrutura de um complemento verbal pode variar mesmo para um mesmo verbo regente. Com fazer-por, o verbo causativo seria um verbo lexical cujo VP seleciona um VP nominalizado, como em (36a) (TURINO BLANCO, 2011). Com infinitivo flexionado, o domínio infinitivo seria um CP completo, considerando o movimento de V-para-C para fins de licenciamento do seu traço de concordância, originário do domínio superior, como em (36b) (GALVES, 2001).

$$
\begin{array}{ll}
\text { a. Fazer-por: } & {\left[\mathrm{VP}_{\mathrm{VP}} \mathrm{V} 1\left[{ }_{\mathrm{VP}-\text { nom }} \mathrm{V}\right]\right]} \\
\text { b. Infinitivo flexionado: } & {\left[{ } _ { \mathrm { CP } } \mathrm { C } \left[\left[_{\mathrm{TP}} \mathrm{T}\left[\left[_{\mathrm{InfP}} \operatorname{Inf}\left[{ }_{\mathrm{vP}} \mathrm{V}\left[\mathrm{VP}_{\mathrm{VP}} \mathrm{V}\right]\right]\right]\right]\right]\right.\right.}
\end{array}
$$

Com fazer-infinitivo e MCE, o verbo causativo seleciona VoiceP (ROBERTS, 2010b), sendo a motivação para isso o fato de, nas duas construções, haver atribuição de Caso acusativo pelo verbo causativo a um argumento do domínio infinitivo, como se mostra em (37a-b):

$$
\begin{array}{ll}
\text { a. Fazer-infinitivo: } & {\left[{ }_{\mathrm{VoiceP}}\right.} \\
\text { b. Marcação de caso excepcional: }\left[v_{\mathrm{P}} \mathrm{V}[\mathrm{VP}\right. & \mathrm{V}]]] \\
{[\mathrm{VoiceP}} & \left.\operatorname{Voice}\left[v_{\mathrm{P}} \mathrm{V}\left[{ }_{\mathrm{VP}} \mathrm{V}\right]\right]\right]
\end{array}
$$

A oposição entre derivação inversa com fazer-infinitivo e direta com MCE se relaciona com a retenção ou doação do traço [u/phi] do núcleo de fase à categoria por ele selecionada.

Primeiro, vejamos o caso da derivação direta de uma sentença como Ele fez os miúdos ler o livro. O traço [u/phi] é doado de Voice a $v$, no passo $(38 \mathrm{a}) ; v$ naturalmente valorará o Caso do argumento interno $o$ livro (acusativo), e o argumento externo (AE ou causado) é concatenado em Spec,VoiceP, no passo (38b); como resultado, a única forma de o argumento externo ter seu Caso valorado envolve uma operação Concordar com o $v$ do domínio finito, no passo (38c). 
(38) Derivação direta - a partir de (37b)

a. $\left[_{\text {VoiceP }}\right.$ Voice $\left.\left[{ }_{\mathrm{vP}} v[\mathrm{u} / \mathrm{phi}]\left[_{\mathrm{VP}} \mathrm{V}\right]\right]\right]$

b. $\left[_{\text {Voicep }}\left[{ }_{\mathrm{AE}}\right.\right.$ os miúdos] Voice $\left[_{\mathrm{vP}}\right.$ ler+ $+v$ [u/phi] o livro $\left.]\right]$

c. $\left[_{\mathrm{TP}}\right.$ ele fez $\left[_{\mathrm{vP}}\right.$ ele fazer $+v\left[_{\mathrm{VoiceP}}\left[_{\mathrm{AE}} \underline{\text { os miúdos }}\right]\right.$ Voice $\left[_{\mathrm{VP}}\right.$ ler o livro ]]]]

Essa derivação mantém a ordem relativa de concatenação dos argumentos na estrutura na ordem final. $\mathrm{O}$ oposto ocorre na derivação inversa, numa sentença como Ele fez ler o livro aos miúdos. $\mathrm{O}$ traço $[\mathrm{u} /$ phi] é retido em Voice, no passo (39a); Voice, em seguida, identificará o $\nu \mathrm{P}$ como alvo (por ser o elemento mais próximo que contém os traços-phi buscados - ver RACKOWSKI; RICHARDS, 2005) e o moverá para o Spec, VoiceP mais externo, no passo (39b); ocorre o movimento de $v \mathrm{P}$ para o especificador acima do ponto em que se concatena o argumento externo, no passo (39b); finalmente, tanto o argumento interno quanto o argumento externo terão seus Casos valorados por núcleos funcionais no domínio superior da oração, o primeiro por $v$ e o segundo por $v_{\text {appl }}$, no passo (39c).

(39) Derivação inversa - a partir de (37a)

a. $\left[{ }_{\mathrm{V} \text { oiceP }}\right.$ Voice $\left.[\mathrm{u} / \mathrm{phi}]\left[v_{\mathrm{P}} \mathrm{V}\left[_{\mathrm{VP}} \mathrm{V}\right]\right]\right]$

b. $\left[_{\text {VoiceP }}\left[v_{\mathrm{P}}\right.\right.$ ler o livro $]\left[_{\mathrm{AE}}\right.$ os miúdos $]$ Voice $\left.[\mathrm{u} / \mathrm{phi}]\right]$

c. $\left[\mathrm{TP} T\left[v_{\text {applP }} v_{\text {appl }}\left[{ }_{\mathrm{vP}} v\left[_{\mathrm{VoiceP}}\left[{ }_{v \mathrm{P}}\right.\right.\right.\right.\right.$ ler o livro $]\left[_{\mathrm{AE}}\right.$ ạs miụ́dọ̣s $]$ Voice $\left.\left.\left.]\right]\right]\right]$

A derivação inversa, por levar um constituinte para a borda da fase VoiceP, abre espaço para o movimento do argumento interno (NP ou pronome) para o domínio superior da oração (ver smuggling em COLLINS, 2005). Uma implicação desse sistema é que a subida de clíticos (com função de argumento interno) é possível exatamente nessa configuração; assim, substituindo o NP argumento interno em (39c) por um clítico, tem-se o resultado em (39c'):

$$
\text { c'. Ele fê-lo ler aos miúdos. }
$$

Vejamos agora as implicações desse sistema para o espectro de variação observado para o PA na Tabela 3. Parece que temos de início duas boas implicações:

- Quanto à marcação: considerando que o infinitivo 
flexionado envolve uma estrutura mais complexa, ele será mais marcado que as demais construções, contrariamente a fazer-por, que é a mais simples e a mais produtiva.

- Quanto à semântica: considerando que na derivação inversa (fazer-infinitivo) há movimento de $v \mathrm{P}$ para Spec, VoiceP mais externo, espera-se que a ação descrita pelo infinitivo esteja em maior evidência, contrariamente ao que acontece com a derivação direta, o que se reflete nas observações de Soares da Silva (2005).

Pensando na questão da distinção entre a ordem VOV com o causativo permissivo (deixar) e com os causativos factitivos (fazer e mandar), afirmei que o primeiro caso corresponde a um MCE espúrio. Considerando a estrutura em que o causado recebe caso acusativo não obstante a presença de uma barreira oracional, isso quererá dizer que o causado com o verbo deixar é um verdadeiro objeto, ou seja, a estrutura infinitiva envolve uma categoria vazia controlada pelo objeto (40b). Evidência disso é a possibilidade de operadores associados a foco, como só, terem escopo restrito sobre o objeto o João com o verbo deixar, mas não com fazer ou mandar (41):

(40) Estruturas de MCE real e espúrio

a. Ela fez/mandou [ ${ }_{V_{\text {Voicep }}}$ o João sair de casa].

b. Ela deixou o João ${ }_{i}\left[{ }_{\mathrm{CP}} c v_{i}\right.$ sair de casa $]$

(41) Associação com foco

a. *? Ela só faz/manda $\left[_{\text {Foco }}\right.$ o João] sair de casa.

b. Ela só deixa $\left[_{\mathrm{FOCO}}\right.$ o João] sair de casa.

Note-se que (41a) só é possível atribuindo-se um significado não-causativo para a sentença com mandar. Teste semelhante a (41) foi proposto por Azoulay-Vicente (1985, p. 152) para o francês, com a estrutura restritiva ne...que:

(42) Associação com foco

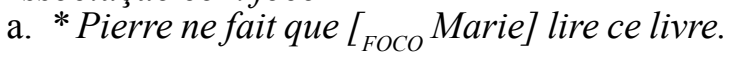

'Pierre só faz Marie ler esse livro.'

b. Pierre ne laisse que $\left[_{\text {FOCO }}\right.$ Marie] lire ce livre. 
'Pierre só deixa Marie ler esse livro.'

A autora interpreta, seguindo Kayne (1975), que a estrutura em (40b) impede que ela sofra a regra de faire-infinitif. Nesse quadro, a ordem semelhante à construção faire-infinitif (VV) é obtida pela seleção de fazer-por, via seleção da estrutura nominalizada em (36a). Essa análise é compatível com os dados diacrônicos do português, tendo em vista que não foram encontrados dados com causado licenciado com caso dativo.

Considerando que o MCE espúrio é uma construção diferente, o que fica por ser explicado quanto às construções causativas do PA é seu necessário alinhamento morfossintático inverso. Para responder a essa questão, julgo ser necessário observar outro parâmetro no PA, o da configuracionalidade discursiva.

\subsection{O parâmetro da configuracionalidade discursiva e o scrambling}

A configuracionalidade discursiva é um parâmetro que separa línguas quanto ao papel que o movimento para uma posição nãoargumental (movimento A', requerido pelos núcleos de fase) tem nas sentenças em geral. A hierarquia desse parâmetro envolverá decisões mais específicas relacionadas à capacidade dos núcleos de fase em licenciar movimentos A'. No caso do núcleo Voice, há que se chamar a atenção para a possibilidade de dois tipos de movimento, um que mira essa categoria e outro que só a utiliza como "entreposto". No primeiro caso é que se observa o fenômeno do scrambling. Diante disso, vale a pena ter uma visão da hierarquia proposta para esse parâmetro, mostrada na Figura 4 (adaptada de ROBERTS, 2010b): 


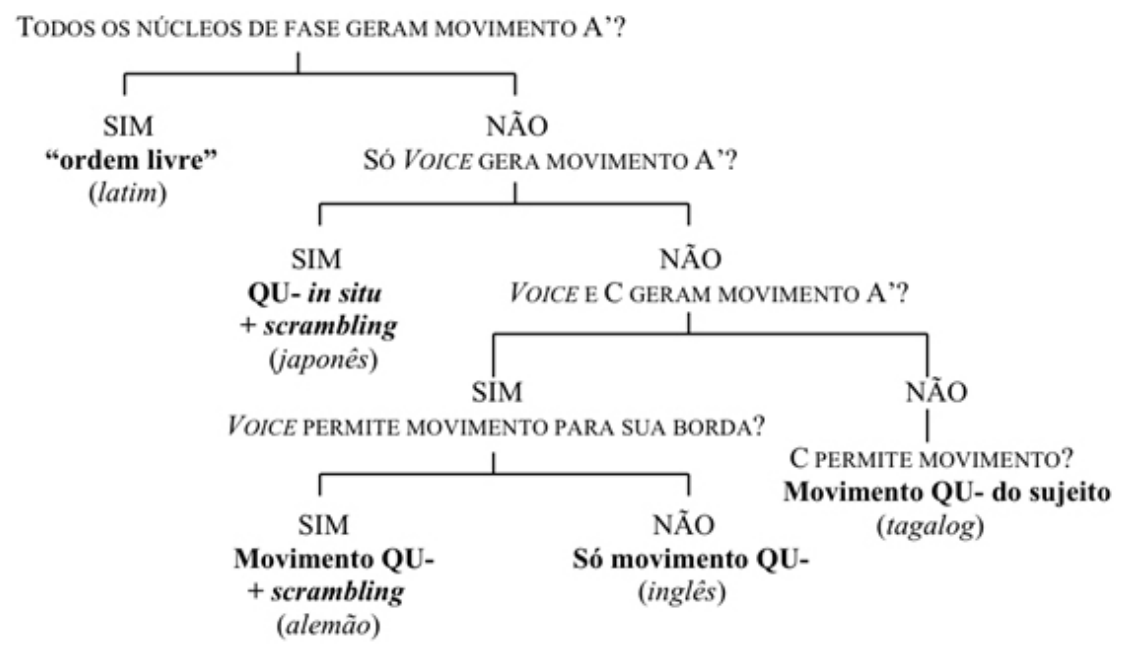

Figura 4- Hierarquia do parâmetro da configuracionalidade discursiva

A questão que imediatamente se coloca é como o PA se classifica quanto à hierarquia demonstrada. Já vimos que essa gramática tinha scrambling, o movimento para a borda de Voice; sabemos também, pela leitura dos textos antigos, que não houve mudanças substanciais quanto à disponibilidade do movimento QU-; resta saber se o PA tinha movimento pela borda de D, ou rumo a uma posição na periferia esquerda da fase CP ou da fase VoiceP. Essas duas opções são observadas em alguns exemplos, em termos do movimento de um PP incluindo um pronome demonstrativo ou um pronome pessoal fraco:

(43) a. ... bem sabem, que disto deveis $\left[_{\text {VoiceP }}\right.$ disto ter $\left[_{D P}\right.$ disto mor sentido disto ]. (Lopes *1380, 7)

b. ... nunqua tal cousa dissera, nem sabia $\left[_{\mathrm{V} \text { oicep }}\right.$ dello $\left[_{\mathrm{DP}}\right.$ dello parte dello ]. (Lopes *1380, 19)

Em (43a) o PP disto ocorre na periferia esquerda da sentença (CP), logo abaixo do complementador, e apresenta valor de foco contrastivo. Em (43b) o PP dello ocorre na periferia do VoiceP, também com valor focal. Nos dois casos, os constituintes em tela tiveram de passar por Spec,DP, considerando que o PP está encaixado no DP argumento interno. Esses fatos me fazem pensar que o PA é uma língua de "ordem livre", 
dando continuidade, quanto a esse aspecto, ao latim tardio. ${ }^{16}$

O scrambling é usualmente entendido como movimento A' (MÜLLER; STERNEFELD, 1984). Considerando os dados do português diacrônico e o sistema de traços apresentado anteriormente, podemos pensar que, no português antigo, o scrambling seria resultante de os traços [u/edge] e [u/phi] serem verificados conjuntamente nos núcleos de fase $\mathrm{C}$ e Voice. Em outras palavras, e enfocando a fase VoiceP, Voice retinha o traço $\left[\mathrm{u} / \mathrm{phi},{ }^{\wedge}\right]$, que desencadeava o movimento do $v \mathrm{P}$ para sua borda, e também tinha o traço [u/edge, ${ }^{\wedge}$ ], que desencadeava o movimento $\mathrm{A}^{\prime}$ do argumento interno para a sua borda mais externa. ${ }^{17}$ No primeiro caso, e considerando também a possibilidade de a borda poder servir de "albergue", e não somente de "entreposto" para um movimento para a periferia esquerda, observa-se o scrambling. Ilustro a derivação do exemplo semelhante a (22) com interpretação de scrambling:

(44) Sagramor fez sa lança voar

a. [ ${ }_{\text {VoiceP2 }}$ Voice[u/phi] [ ${ }_{v P 2}$ voar [ ${ }_{\mathrm{VP} 2}$ sara lança ]]]

[Concatenação até VoiceP ${ }_{2}$ ]

b. VoiceP2 $_{v \mathrm{PP} 1}$ voar sa lança ] Voice [u/phit]

[movimento de $v \mathrm{P}$ ]

c. $\left[_{V_{\text {oiceP2}}}\left[\left[_{V_{\text {oiceP }}}\left[{ }_{D P}\right.\right.\right.\right.$ sa lança $]\left[_{\nu \mathrm{P} 2}\right.$ voar sa lanȩa $]$

Voice $\left.\left._{\text {[u/edge] }}\right]\right]$

[scrambling do DP]

d. $\left[_{V \text { oiceP1 }}\right.$ Sagramor $\left[_{\nu P 1}\right.$ fazer $\left[{ }_{V P 1}\right.$ fazer

$\left[_{\text {VoiceP }}\left[{ }_{\text {VoiceP }}\left[{ }_{D P}\right.\right.\right.$ sa lança $]\left[_{v P}\right.$ voar sa lanȩa $]$

Voice $\left.\left.\left.\left.\left._{\text {[tredge] }}\right]\right]\right]\right]\right]$

[Concatenação até VoiceP ${ }_{1}$ ]

e. $\left[_{T P}\right.$ Sagramor fez $\left[_{V o i c e P 1}\right.$ Sagramor $\left[_{v P 1}\right.$ fazer

$\left[_{\mathrm{VP} 1}\right.$ fazer $\left[{ }_{\text {VoiceP }}\left[\left[_{\text {VoiceP }}\left[{ }_{D P}\right.\right.\right.\right.$ sa lança $]\left[_{v P}\right.$ voar

[sa lanȩ̧a] Voice $\left.{ }_{\text {[tredge] }}\right]$ ]]]]]]

[movimentos de DP e de V]

\footnotetext{
${ }^{16}$ As diferenças face ao latim clássico incluem a limitação à subextração a certos tipos de PPs no PA, o que pode ser um efeito de mudanças internas atuando sobre a sintaxe do DP.

${ }^{17}$ Semelhantemente a Chomsky (2004), considero que os movimentos A e A' ocorrem separadamente, sendo a cópia mais alta a pronunciada.
} 
Entendo, dessa forma, que o scrambling no PA é resultante da conjunção da retenção do traço $\left[\mathrm{u} / \mathrm{phi},{ }^{\wedge}\right]$ em Voice, com a presença do traço $\left[\mathrm{u} / \mathrm{edge},{ }^{\wedge}\right]$ nesse mesmo núcleo, resultando no movimento do elemento argumental mais próximo para a borda. O que acrescento em termos de pressupostos gerais é hipotetizar que este traço acarreta aquele. Em outras palavras, apresento a generalização em (45):

(45) Relação entre scrambling e alinhamento inverso

Se uma língua tem scrambling, ela terá alinhamento inverso com VoiceP.

Não posso aqui desenvolver totalmente as consequências dessa previsão, mas a intuição tem a ver com o fato de que a não observância da correlação acima geraria estruturas em que seria impossível distinguir um elemento A' de um elemento A, porque o movimento para realizar a operação de scrambling resultaria invisível. Enfatizo ainda que a generalização só se aplica a um complemento VoiceP, como nas estruturas em (37). Uma ilustração é o francês que, apesar de não ter scrambling generalizado, apresenta-o com elementos foneticamente leves: certos advérbios (mieux, mal, bien) e quantificadores flutuantes (tout, tous, rien) (CINQUE, 2002). Considerando ainda que quantificadores flutuantes se adjungem aos NPs que eles modificam - o que só pode ocorrer em posições A', como propõe Bošković (2004, p. 707) -, há um passo na derivação em que tous e o NP/pronome estão numa posição "embaralhada", numa frase como Ils nous font tous sortir ("eles nos fazem sair a todos"), como se nota crucialmente em (46c) (o sinal de igualdade indica cliticização morfológica):

(46) Ils nous font tous sortir.

a. $\left[_{\mathrm{Voice} 22}\right.$ Voice $[\mathrm{u} / \mathrm{phi}]\left[_{v \mathrm{pP} 2}\right.$ nous $=$ sortir $\left[{ }_{\mathrm{VP} 2}\right.$ sortir nous $\left.\left.]\right]\right]$

b. $\left[\left[_{\text {Voicep2 }}\left[{ }_{v P 1}\right.\right.\right.$ nous $=$ sortir $]$ Voice $[\mathrm{u} /$ phit $\left.]\right]$

c. $\left[\right.$ Voicep2 $\left[\left[_{\text {Voicep }}\left[{ }_{\mathrm{QP}}\right.\right.\right.$ nous $=$ tous $]\left[v_{\mathrm{P} 2}\right.$ nous $=$ sortir $]$ Voice $\left.\left.\left.\left._{[\text {[tedgeg }}\right]\right]\right]\right]$

d. $\left[_{\nu P 1}\right.$ nous $=$ faire $\left[_{V P 1}\right.$ faire $\left[_{V o i c e P}\left[_{V o i c e P}\left[{ }_{Q P}\right.\right.\right.$ tous $=$ tous $]\left[v_{\mathrm{P}}\right.$ sortir $]$ Voice $\left.\left.\left.\left._{[\text {twedge }]}\right]\right]\right]\right]$

e. $\left[_{\mathrm{TP}}\right.$ ils nous $=$ font $\left[\left[_{\mathrm{VoiceP} 1}\right.\right.$ its $\left[_{v \mathrm{PP}}\right.$ faire $\left[_{\mathrm{VP} 1}\right.$ faire $\left[_{\mathrm{VoiceP}}\left[_{\mathrm{VoiceP}}\left[_{\mathrm{QP}}\right.\right.\right.$ nots $=$ tous] $\left[{ }_{\nu \mathrm{P}}\right.$ sortir] Voice $\left.{ }_{[\text {tredge] }}\right]$ ]]] 
Considerando que o francês não tem MCE real com estruturas causativas, a previsão em (45), que deriva de uma generalização descritiva, se mantém para a comparação feita até aqui, que correlaciona propriedades do PA e com aquelas do francês.

\section{Análise formal, parte II: a mudança do português antigo ao português clássico}

O que ficou por explicar é como e por que o sistema gramatical do PA teria mudado, tornando-se o que se encontra no PCl. Para tanto, apresento, a seguir, os dados com detalhe no aspecto do preenchimento da posição interverbal, a qual está diretamente relacionada ao scrambling. Uma vez que esse fenômeno engloba diferentes tipos de elementos, classifico os dados de causativas ativas com preenchimento, excluindo os casos não-ambíguos de $\mathrm{MCE}$, entre argumentos e adjuntos, e dividindo, logo após, os elementos argumentais entre aqueles selecionados pelo $\mathrm{V}_{\text {caus }}$ (causador) e aqueles selecionados pelo $\mathrm{V}_{\text {inf }}$ (outro), como se mostra na Tabela 4.

Tabela 4 - Tipo de elemento em posição interverbal nas construções causativas ativas

\begin{tabular}{llll}
\hline Século/Elemento & -arg & $\begin{array}{l}\text { +arg: } \\
\text { causador }\end{array}$ & $\begin{array}{l}\text { +arg: } \\
\text { outro }\end{array}$ \\
\hline Séc. XIV & & 20 & 6 \\
Séc. XV & 43 & 15 & 16 \\
Séc. XVI & 28 & 14 & 2 \\
Séc. XVII & 38 & 19 & 0 \\
\hline
\end{tabular}

Os dados mostram que há uma mudança quantitativa brusca nos elementos argumentais "embaralhados" (agrupados na coluna +arg: outro) entre os séculos XV e XVI, passando de 16 para 2 ocorrências. Tais elementos podem ser, em termos de função gramatical, um causado, um argumento interno ou um quantificador flutuante, como mostram os exemplos abaixo:

(47) Elementos argumentais "embaralhados"

a. ...e fezeram muitos deles saltar polas freestas (Demanda 289, 104d) 
b. ...o mui grande amor que eu sempre houve a vós e a eles me faz esto dizer. (Demanda 28, 9a)

c. ...e os mandou todos soltar, e livrar de cativeiro. (Galvão $* 1435,8)$

Isso me leva a confirmar a intuição de que há uma relação direta entre a perda do scrambling de elementos argumentais e a emergência da marcação de caso excepcional. Note-se, nesse sentido, que nos dados dos autores nascidos no século XVI há ainda várias ocorrências de scrambling de adjuntos (- arg, na tabela), que seriam adjungidos em Spec, VoiceP, razão pela qual podem coocorrer com outros advérbios ou com elementos argumentais. Finalmente, os dois dados de elementos + arg: outro encontrados no século XVI provavelmente se devem a resquícios da gramática do PA, como é de se esperar em situações de competição de gramáticas que acompanham mudanças paramétricas.

Dentro do sistema descrito anteriormente, espera-se que o PA tenha sofrido, portanto, uma mudança quanto ao parâmetro de configuracionalidade discursiva, deixando de ser uma língua em que todos os núcleos de fase geram movimento A' - ou seja, uma língua de "ordem livre", similar ao latim -, para tornar-se uma língua em que só C gera movimento A', semelhantemente ao inglês.

Essa mudança no parâmetro de configuracionalidade discursiva teria efeitos "catastróficos", porque envolve a convenção de marcação em (34): considerando que o conjunto de núcleos $\mathrm{N}$ referido nessa convenção é $\{C, D\}$, tem-se que o padrão geral de marcação do PA era não-marcado para $[+$ movimento], passando a ser marcado. Em outras palavras, houve a mudança de (i) para (ii):

(i)

(ii) Voice $[\mathrm{u} / \mathrm{edge}]$ $\rightarrow \mathrm{C} / \mathrm{D}\left[\mathrm{u} /\right.$ edge, $\left.{ }^{\wedge}\right]$ não-marcado

$\rightarrow \mathrm{C} / \mathrm{D}\left[\mathrm{u} /\right.$ edge, $\left.{ }^{\wedge}\right]$ marcado

De fato, não se observam mais subextrações de DPs em dados do $\mathrm{PCl}$, semelhantes aos mencionados em (43).

Tendo em vista a relação entre traços $\left[\mathrm{u} / \mathrm{edge},{ }^{\wedge}\right] \mathrm{e}\left[\mathrm{u} / \mathrm{phi},{ }^{\wedge}\right] \mathrm{em}$ Voice, conforme a previsão em (47), tem-se que a mudança no parâmetro da configuracionalidade discursiva implicará a não-exigência de retenção 
de traços $[\mathrm{u} / \mathrm{phi}, \wedge]$ em Voice. Isso, por sua vez, permitirá que a derivação direta tenha lugar, como se observou em (40a), com a implicação prática de a marcação de caso excepcional poder ser derivada no $\mathrm{PCl}$.

A explicação para essa correlação fica mais simples se for pensada em termos de opacidade dos dados para o aprendiz de língua. Assim, voltando ao exemplo (22),

(22) E Sagramor fez [s lança voar em peças]

nota-se que o aprendiz da gramática do PA tinha à sua disposição evidências de contextos distintos da construção causativa, para identificar que havia uma regra de scrambling de curta distância em sua gramática, que o permitiam interpretar o elemento sublinhado em (22) como constituinte "embaralhado". Já o falante do $\mathrm{PCl}$, por não encontrar, nos seus dados linguísticos primários, evidência de scrambling, reanalisa esse exemplo como sendo evidência da derivação direta, em que sa lança se move por movimento A, e não por movimento A'.

Passo agora a observar diferenças entre a proposta aqui apresentada face às demais oferecidas no âmbito da linguística moderna. Primeiro, entendo que a proposta de mudança baseada na perda do scrambling é mais abrangente que aquela apresentada em Davies (1996). Para o autor, a história de tais construções remonta ao latim medieval, quando ocorre a fusão morfológica dos infinitivos passivos com os ativos, ficando ambos com a terminação $-e$ (exemplos de DAVIES, 1996, exemplo (56)):

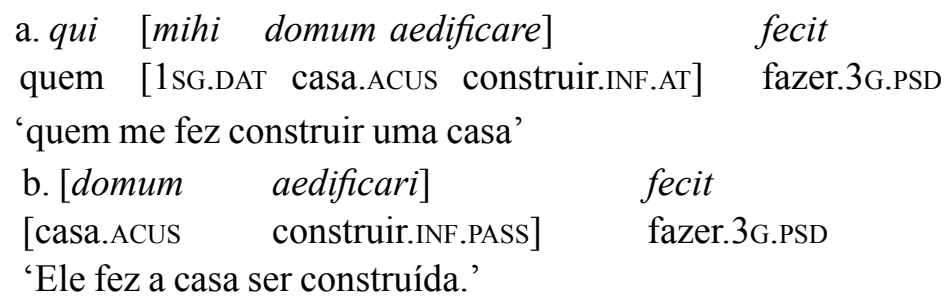

Segundo Davies (1996), a contraparte de (48b), um infinitivo passivo sem agente expresso (um infinitivo reduzido, para DAVIES, 1996), prevaleceria no PA; mas, com o tempo, a interpretação ativa teria ganhado terreno, ou seja, o sujeito realizado teria se tornado mais 
frequente, o que levou à reanálise do complemento do verbo causativo como uma estrutura não-reduzida. Apesar de ser coerente com a grande quantidade de dados de união de orações sem causado expresso no PA como foi mostrado no grupo de dados União de Orações [-CAUSADO], na Figura 3 -, essa proposta não explica por que o significado ativo teria avançado nos contextos sem causado expresso. É nesse sentido que a presente proposta de reanálise mencionada logo acima preenche uma lacuna explicativa.

Além disso, tendo em vista a implicação derivada da presente proposta de que há uma relação de marcação derivada do tamanho relativo das estruturas de infinitivo flexionado e de marcação de caso excepcional - (36b) e (37b) -, a presente proposta também prevê que a construção de infinitivo flexionado surja no complemento de verbos causativos posteriormente à construção de marcação de caso excepcional. Isso está de acordo com os resultados apresentados em (29). Além desses exemplos, a perda da variante (10f') em favor do caso de identificação de construções causativas em (10f) - resultante da perda do scrambling de argumentos - sugere que a ambiguidade entre infinitivo flexionado e marcação de caso excepcional precede a ocorrência de casos nãoambíguos de infinitivo flexionado, sendo a construção envolvida na ambiguidade semelhante àquela mostrada em (49) $=(14)$.

$$
\begin{aligned}
& \text {... mandando [ } \underline{\text { um Mouro de recado dar aviso aos da }} \\
& \text { forteleza]. (Couto } * 1542 \text { In TRANNIN, 2010) }
\end{aligned}
$$

Isso contrasta com a proposta de Martins (2004), que apresenta o exemplo em (50) como a fonte para a reanálise que teria gerado a construção de infinitivo flexionado no complemento de verbos causativos, devido à possibilidade de duas interpretações: uma em que a coordenação ocorre no nível do predicado causativo, tendo o infinitivo um uso arcaico, como optativo (com o significado 'peyte' 'pague'); outra, em que a coordenação ocorre no nível do domínio infinitivo, ficando o verbo causativo elíptico. ${ }^{18}$

\footnotetext{
${ }^{18} \mathrm{O}$ problema relacionado ao uso do infinitivo flexionado em contexto optativo remonta às origens dessa forma verbal, desde o latim, e seu tratamento ultrapassa os objetivos do presente artigo.
} 
(50) Mandamos peytar áá parte aguardante $\mathrm{C}$ maravedis e [o prazo ficar em sa forteleza]. (Documento 1287. In MAIA, 1986, p. 250)

No entanto, por ser a estrutura em (50) muito pouco frequente e por não serem atestados dados não-ambíguos de infinitivo flexionado nem no PA, nem no PCl, acredito que (49) exemplifica o tipo de estrutura a partir da qual a nova construção de infinitivo flexionado veio a ser gerada.

\section{Implicações da proposta paramétrica}

Antes de concluir este trabalho, discuto duas implicações da proposta paramétrica aqui apresentada: a primeira, observável mais claramente a partir de outra construção semelhante à "união de orações", a "reestruturação", também um tipo de predicado complexo; e a segunda, uma implicação mais geral para a compreensão da mudança entre PA e $\mathrm{PCl}$ em termos paramétricos.

Quanto ao primeiro ponto, a análise formal do PA explorou as seguintes hipóteses:

- o PA era uma língua de "ordem livre” quanto ao parâmetro da configuracionalidade discursiva;

- o PA, por ter scrambling de argumentos, retinha traços $[\mathrm{u} / \mathrm{phi}, \wedge]$ em Voice.

Tais hipóteses implicam o seguinte corolário: em outras estruturas em que um verbo regente seleciona uma estrutura reduzida VoiceP, haverá movimento obrigatório de clíticos argumentos internos do domínio infinitivo para o domínio superior, e a possibilidade de movimento de outros elementos presentes no material movido para a borda de VoiceP. O primeiro fenômeno é referido na literatura como subida de clíticos e pode ser observado na construção de "reestruturação", em que há um verbo temporal, aspectual ou modal (auxiliar ou semi-auxiliar) selecionando VoiceP (ou $v \mathrm{P}$, dependendo da representação escolhida; ver ANDRADE, 2010). Esse fenômeno é opcional no PEM, como indicam os seguintes exemplos, extraídos da rede: 
(51) a. ... eu já não o posso ver, nem ouvir e muito menos ler o que escreve. (Disponível em: <http://www.dn.pt forums/p/2037981/6986191. aspx>. Acesso em: 10 jan. 2014)

b. Não posso vê-lo mais, é um mentiroso.

(Disponível em: <http://www.dn.pt/forums/p/997432/3159812. aspx>. Acesso em: 10 jan. 2014)

De fato, vários autores observaram que não só o PA, como também outras línguas românicas antigas, apresentavam subida de clíticos obrigatória, como resume Wanner (1987). Em estudo baseado em corpus, Andrade e Fischer (2013) observam que o português antigo e o catalão antigo apresentavam de fato subida de clíticos obrigatória, sendo algumas exceções consequência do paralelismo com outras estruturas ou da gramaticalização, em consonância com o princípio em (25b). Demonstram ademais que, além da subida obrigatória exemplificada num dado como (52a), o PA também apresentava fronteamento estilístico, fenômeno que expressa o movimento do $\mathrm{V}_{\text {inf }}$ (em alguns casos com uma preposição subcategorizada pelo $\mathrm{V}$ superior) para a periferia esquerda da sentença, portanto, sobre o $\mathrm{V}$ auxiliar podesse:

(52) a. D'esta rreposta forom elles mui contentes, e trabalharomsse d'açallmar e bastecer melhor o logar, que sse lhe tall cousa

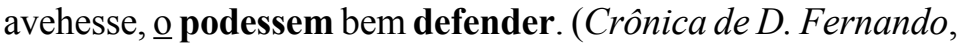
150. In ANDRADE; FISCHER, 2013)

b. ...rresponde-sse que esto nom parece d'outorgar, ca, sse assi fora, nom era a tregua cousa que se encobrir podesse... (Crônica de D. Fernando, 142. In ANDRADE; FISCHER, 2013)

Os autores interpretam os exemplos em (52) como consequência de smuggling para a borda de VoiceP. Note-se que em (52b) o clítico é movido "de carona" com o $\mathrm{V}_{\text {inf }}$ encobrir. Finalmente, no que se refere à transição para o português clássico e para o catalão moderno, os autores relacionam a perda da subida de clíticos obrigatória com a perda do fronteamento estilístico, sendo ambas as alterações resultantes de uma mudança específica na periferia esquerda dessas línguas românicas, que se expressava na possibilidade de marcar um foco estreito recaindo sobre $(c l+) V_{\text {inf }}$ por meio de movimento, em vez de realizar uma cópia mais baixa do elemento focalizado. Essa proposta se encaixa na ideia 
de que o PA era uma língua de "ordem livre", cuja periferia esquerda expressava uma série de elementos informacionalmente marcados por meio de movimentos explícitos na sintaxe.

Quanto à questão mais geral das implicações desta proposta para a periodização do português, entendo que ela fortalece a proposta em Galves, Namiuti e Paixão de Sousa (2006), de que a mudança do PA ao $\mathrm{PCl}$ se situa mais ou menos um século antes do que normalmente se supõe. Além disso, em se considerando o parâmetro da configuracionalidade discursiva, compreende-se também a razão para que o fenômeno apontado como principal evidência para a mudança - a interpolação generalizada de clíticos - seja afetado exatamente no século XV. Como apontou Namiuti (2008), a interpolação generalizada consiste no movimento opcional de clíticos para (um núcleo de) $\mathrm{C}$, com posterior afixação do clítico à direita do complementador, por inversão prosódica, a fim de explicar sua adjacência face a esse elemento. Por sua vez, a interpolação generalizada está vinculada à presença de elementos proclisadores, que apontam para um contexto informacional que, apesar de ainda carecer de maior entendimento quanto à sua raison d'être, inclui a expressão do foco. Considerando ainda o que diz Roberts (2010b), é de se esperar que a mudança do PA ao PCl esteja relacionada a mudanças na morfologia do DP, já que há uma certa correlação entre "ordem livre" e não-expressão de determinantes. $\mathrm{O}$ mesmo não se espera da mudança entre o $\mathrm{PCl}$ e o $\mathrm{PE}$, que não será tão catastrófica, restringindo-se a questões de sintaxe - dependentes, às vezes, da observação de evidências indiretas.

\section{Conclusão}

Os dados do português antigo e clássico referentes às construções causativas com complemento infinitivo demonstram uma distribuição distinta face às variedades contemporâneas estudadas (PB e PEM). Procurei demonstrar, a partir de estudo baseado em corpus, que os verbos causativos do PA se restringiam à construção de "união de orações", considerando o princípio de que a existência de dados não-ambíguos é crucial para a reanálise de determinada construção, na gramática internalizada de cada falante. Tendo em vista a assunção de que causativas mono-oracionais têm pelo menos dois tipos de derivação, direta ou inversa - o que está atrelado ao parâmetro de doação ou retenção de traços $\left[\mathrm{u} /\right.$ phi, $\left.{ }^{\wedge}\right]$ em Voice -, propus que o PA apresenta uma correlação 
entre "ordem livre" de palavras e alinhamento inverso no complemento dos verbos causativos, derivado de uma generalização descritiva que faz com que haja retenção de $[\mathrm{u} / \mathrm{phi}, \wedge]$ em Voice se esse núcleo tem $[\mathrm{u} /$ edge, ${ }^{\wedge}$ ], como consequência da tipologia do PA quanto ao parâmetro da configuracionalidade discursiva.

O estudo de corpus, realizado com o auxílio de uma matriz de critérios de classificação dos dados, possibilitou a identificação do momento em que a construção de marcação de caso excepcional surgiu na história do português. A partir desse resultado considerei que a perda do scrambling de curta distância teria sido a causa da reanálise que levou ao surgimento da construção de marcação de caso excepcional no PCl. Após esse período, ocorreriam casos de ambiguidade entre marcação de caso excepcional e infinitivo flexionado, os quais teriam permitido o surgimento da construção de infinitivo flexionado nesse contexto, já no PEM. As implicações da proposta paramétrica se replicam a fenômenos típicos do PA, tais como: a subida de clíticos obrigatória, o fronteamento estilístico e a interpolação generalizada, este último já apontado em Galves, Namiuti e Paixão de Sousa (2006) como fenômeno indicativo da mudança do PA ao PCl.

\section{Referências}

ACHARD, M. Representation of Cognitive Structures: Syntax and Semantics of French Sentential complements. Berlin \& New York: Mouton de Gruyter, 1998.

AISSEN, J. Differential Object Marking: Iconicity vs. Economy. Natural Language \& Linguistic Theory 21, n. 3, p. 435-483, 2003.

ANDRADE, J. C. As construções causativas do português do Brasil na perspectiva gerativa. Dissertação (Mestrado em Linguística). 2002. 85p. Universidade de Brasília, Brasília, 2002.

ANDRADE, A. L. de. A subida de clíticos em português: um estudo sobre a variedade europeia dos séculos XVI a XX. Dissertação (Doutorado em Linguística). 2010.360p. Universidade Estadual de Campinas, Campinas, 2010.

ANDRADE, A. L.; FISCHER, S. Degrammaticalisation Indices in Iberian Complex Predicates? Ms. Universidade Estadual de Campinas/ Universität Hamburg, 2013. 
AZOULAY-VICENTE, A. Les tours comportant l'expression de + adjectif. Genève: Droz, 1985.

BELLETTI, A. Aspects of the Low IP Area. In: RIZZI, L. (Ed.). The Structure of IP and CP. The Cartography of Syntactic Structures. v. 2. Oxford: Oxford University Press, 2004. p. 16-51.

BIBERAUER, T.; HOLMBERG, A. \& ROBERTS, I. A Syntactic Universal and its Consequences. Ms. University of Cambridge, 2010. Disponível em: <http://research.ncl.ac.uk/linearization/BHR_2010.pdf>. Acesso em: 15. set. 2012.

BORGES, D. V. C. Construções causativas no português do Centro-Oeste nos séculos XVIII-XIX e no português atual. 2008. 144 p. Dissertação (Mestrado em Linguística). Universidade de Brasília, Brasília, 2008.

BOŠKOVIĆ, Ž. Be Careful Where you Float your Quantifiers. Natural Language and Linguistic Theory 22, p. 681-742, 2004.

CHOMSKY, N. Derivation by Phase. In: KENSTOWICZ, M. (Ed.). Ken Hale: A Life in Language. Cambridge, MA: MIT Press, 2001. p. 1-52.

CHOMSKY, N. Beyond Explanatory Adequacy. In: BELLETTI, A. (Ed.). Structures and Beyond. Oxford: Oxford University Press, 2004. p. 104-131.

CHOMSKY, N. On Phases. In: FREIDIN, R.; OTERO, C.; ZUBIZARRETA, M.-L. (Eds.). Foundational Issues in Linguistic Theory: Essays in Honor of Jean-Roger Vergnaud. Cambridge, MA: MIT Press, 2008. p. 133-166.

CINQUE, G. A Note on "Restructuring" and Quantifier Climbing in French. Linguistic Inquiry, n. 33, v. 4, p. 617-636, 2002.

COLLINS, C. A Smuggling Approach to the Passive in English. Syntax, v. 8, n. 2, p. 81-120, 2005.

DAVIES, M. The Diachronic Evolution of the Causative Construction in Portuguese. Journal of Hispanic Philology, v. 17, p. 262-292, 1996.

DIAS, A. E. da S. Syntaxe histórica portuguêsa. 2. ed. Lisboa: Livraria Clássica Editora, 1933.

GALVES, C. Infinitivo flexionado e legitimação de Agr. In: GALVES, C. Ensaios sobre as gramáticas do português. Campinas: Editora da Unicamp, 2001. p. 181-194. 
GALVES, C.; ABAURRE, M. B. M. Os clíticos no Português Brasileiro: elementos para uma abordagem sintático-fonológica. In: CASTILHO, A.; BASÍLIO, M. (Org.). Gramática do Português Falado, v. IV: Estudos Descritivos. Campinas: Editora da UNICAMP / São Paulo: Fapesp, 1996. p. 273-320.

GALVES, C.; FARIA, P. Corpus Informatizado do Português Tycho Brahe. 2010. Disponível em: <www.tycho.iel.unicamp.br/ tycho/ corpus/>. Acesso em: 10 out. 2013.

GALVES, C.; NAMIUTI, C.; PAIXÃO DE SOUSA, M. C. Novas perspectivas para antigas questões: revisitando a periodização da língua portuguesa. In: ENDRUSCHAT, A., KEMMLER, R.; SCHÄFERPRIESS, B. (Org.). Grammatische Strukturen des europäischen Portugiesisch: Synchrone and diachrone Untersuchungen zu Tempora, Pronomina, Präprositionen und mehr. Tübingen: Calepinus Verlag, 2006. p. 45-74.

GONÇALVES, A. P. L. M. Predicados complexos verbais em contextos de infinitivo não preposicionado do português europeu. 1999. 502 p. Tese (Doutorado em Linguística). Universidade de Lisboa, Lisboa, 1999.

GONÇALVES, A.; DUARTE, I. Construções causativas em português europeu e em português brasileiro. In: CORREIA, C. N.; GONÇALVES, A. (Org.). Actas do XVI Encontro Nacional da Associação Portuguesa de Linguística. Lisboa: APL, 2001. p. 657-671.

GUASTI, M. T. Analytic Causatives. In: EVERAERT, M.; VAN RIEMSDIJK, H. The Blackwell Companion to Syntax, v. 1. London: Blackwell, 2006. p. 142-172.

KAYNE, R. S. French Syntax: the Transformational Cycle. Cambridge, MA: MIT Press, 1975.

KAYNE, R. S. The Antisymmetry of Syntax. Cambridge, MA: MIT Press, 1994.

MAIA, C. A. História do Galego-Português. Coimbra: INIC, 1986.

MARTINS, A. M. The Loss of IP-scrambling in Portuguese: Clause Structure, Word Order Variation and Change. In: LIGHTFOOT, David W. (Ed.). Syntactic Effects of Morphological Change. Oxford/New York: Oxford University Press, 2002. p. 232-248. 
MARTINS, A. M. Ambiguidade estrutural e mudança linguística: A emergência do infinitivo flexionado nas orações complemento de verbos causativos e perceptivos. In: BRITO, A. M.; FIGUEIREDO, O.; BARROS, C. (Org.). Linguística Histórica e História da Língua Portuguesa: Actas do Encontro de Homenagem a Maria Helena Paiva. Porto: Universidade do Porto, 2004. p. 197-225.

MENEZES DA SILVA, G. A valência do predicador 'chamar' na diacronia do português. 2010. 177 p. Dissertação (Mestrado em Linguística). Universidade Estadual de Campinas, Campinas, 2010.

MÜLLER, G.; STERNEFELD, W. Scrambling as A-bar Movement. In: CORVER, N.; VAN RIEMSDIJK, H. (Eds.). Studies on Scrambling: Movement and Non-movement Approaches to Free Word-Order Phenomena. Berlin/New York: Mouton de Gruyter, 1984. p. 331-385.

NAMIUTI, C. Aspectos da história gramatical do português. Interpolação, negação e mudança. Tese (Doutorado em Linguística). IEL/UNICAMP, Campinas, 2008.

NEVINS, A. Haplological Dissimilation at Different Stages of Exponence. In: TROMMER, J. (Ed.). The Morphology and Phonology of Exponence. Oxford: Oxford University Press, 2012. p. 84-116.

PEREIRA, E. C. Gramática histórica. 9. ed. São Paulo: Nacional, 1935. RACKOWSKI, A.; RICHARDS, N. Phase Edge and Extraction: A Tagalog Case Study. Linguistic Inquiry 36, n. 4, p. 565-599, 2005.

RAPOSO, Eduardo P. A construção 'União de Orações' na gramática do português. 1981. Tese (Doutorado em Linguística). Universidade de Lisboa, Lisboa, 1981.

ROBERTS, I. Agreement and Head Movement: Clitics, Incorporation and Defective Goals. Cambridge, MA: MIT Press, 2010a.

ROBERTS, I. Macroparameters and Diachrony. Ms. [Workshop Gramaticalização: Abordagens Formais e Funcionais, Campinas], 2010b.

SAID ALI, M. Gramática histórica da língua portuguesa. 3. ed. São Paulo: Melhoramentos, 1964.

SALLES, H. M. L. A ordem dos termos na oração e a sintaxe de construções causativas no português brasileiro. Ms. [XVI Congresso Internacional da ALFAL, Alcalá de Henares], 2011. 
SOARES DA SILVA, A. Revisitando as construções causativas e perceptivas em português: significado e uso. In: DUARTE, I.; FARIA, I. (Org.). Actas do XX Encontro Nacional da Associação Portuguesa de Linguística. Lisboa: APL, 2005. p. 855-874.

TORRES MORAIS, M. A. T.; SALLES, H. M. M. L. Parametric Change in the Grammatical Encoding of Indirect Objects in Brazilian Portuguese. Probus 22, p. 181-209, 2010.

TRANNIN, J. B. Aspectos sintáticos do infinitivo com verbos causativos no português europeu: uma abordagem diacrônica. 2010. 126 p. Dissertação (Mestrado em Linguística). Universidade Estadual de Campinas, Campinas, 2010.

TUBINO BLANCO, M. Causatives in Minimalism. Amsterdam: John Benjamins, 2011.

WANNER, Dieter. The Development of Romance Clitic Pronouns: from Latin to Old Romance. Berlin \& New York: Mouton de Gruyter, 1987.

WURMBRAND, S. Infinitives: Restructuring and Clause Structure. Berlin: Mouton de Gruyter, 2003.

XAVIER, M. F. Corpus informatizado do Português Medieval. 2011. Disponível em: <cipm/fcsh.unl.pt/>. Acesso em: 25 fev. 2013. 